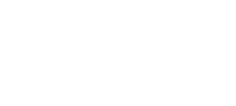

\title{
Cyclodextrin-scaffolded amphiphilic aminoglucoside clusters: self-assembling and gene delivery capabilities $\dagger$
}

\author{
Eva M. Aguilar Moncayo, ${ }^{a}$ Nicolas Guilloteau, ${ }^{b}$ Céline Bienvenu, ${ }^{b}$ \\ José L. Jiménez Blanco, ${ }^{* a}$ Christophe Di Giorgio, ${ }^{\text {b }}$ Pierre Vierling, ${ }^{b}$ \\ Juan M. Benito, ${ }^{C}$ Carmen Ortiz Mellet ${ }^{a}$ and José M. García Fernández ${ }^{c}$
}

Received (in Montpellier, France)

30th April 2014,

Accepted 31st July 2014

DOI: 10.1039/c4nj00700j

www.rsc.org/njc
Precise control over the architecture of gene carriers is instrumental to manipulate gene delivery efficiency. Combining cationic centers and carbohydrate motifs into monodisperse architectures has been proposed as a suitable strategy to impart nucleic acid condensation abilities while preserving biocompatibility. Herein, we have assessed the influence of the arrangement and orientation of cationic elements on the self-assembling and gene transfer capabilities of polycationic glycoamphiphilic cyclodextrins (pGaCDs). For such purposes, a series of cyclodextrin multiconjugates bearing aminoglucoside motifs at their primary rim and hexanoyl chains at the secondary positions were synthesized. In the presence of pDNA, pGaCDs self-assemble into nanoaggregates that promote cellular uptake and gene expression in COS-7 cells with efficiencies that are intimately associated with the arrangement of amino functionalities imposed by the aminoglucoside antennae onto the cyclodextrin-scaffolded cluster. Although transfection efficiencies were lower than those observed for polyethyleneimine (PEI)-based polyplexes and previously-reported polycationic amphiphilic cyclodextrins (paCDs), the results reported herein illustrate (i) the dramatic influence that subtle architectural modifications exert on the supramolecular organization of pGaCDs and (ii) the virtues of monodisperse systems for tailoring gene transfer capabilities.

\section{Introduction}

Gene therapy, involving the introduction and expression of foreign gene material into cells, bears great promise to cure a wide range of genetic as well as acquired diseases. ${ }^{1,2}$ Its effective development critically depends on the design of appropriate delivery systems to carry out compaction, protection, cell internalization and timely release of the gene payload. Viral vectors have been proven to be highly efficient gene delivery agents. However, despite success, ${ }^{3}$ this approach is seriously limited due to immunogenicity and toxicity risks. ${ }^{4}$ Alternatively, research on synthetic gene delivery systems has gained momentum. Nonviral gene vectors, e.g. cationic polymers or lipids, ${ }^{5}$ bear important safety advantages over viral approaches, ${ }^{6,7}$ as well as lower cost and the ease of production. They also offer alternative

\footnotetext{
${ }^{a}$ Departamento de Química Orgánica, Facultad de Química, Universidad de Sevilla, C/Prof. García González 1, E-41012 Sevilla, Spain.E-mail: jljb@us.es

${ }^{b}$ LCMBA UMR 6001, Université de Nice Sophia Antipolis - CNRS, 28, Avenue de Valrose, F-06100 Nice, France

${ }^{c}$ Instituto de Investigaciones Químicas, CSIC - Universidad de Sevilla, Américo Vespucio 49, E-41092 Sevilla, Spain

$\dagger$ Electronic supplementary information (ESI) available: NMR spectra of compounds 8-20 and 2-4. See DOI: 10.1039/c4nj00700j
}

mechanisms for gene material delivery, eventually resulting in improved pharmacokinetics and pharmacodynamics. ${ }^{8,9}$ The overall positive surface electrostatic potential of the corresponding complexes with nucleic acids (polyplexes or lipoplexes) promotes adhesion to negatively charged proteoglycans on the outer face of the cell membrane, thus facilitating cellular uptake and transfection. ${ }^{10,11}$ Yet, the application of non-viral vectors to humans has been, with remarkable exceptions, ${ }^{12,13}$ held back by their poorer delivery efficiency.

Lessons learned from the vast amount of research on non-viral gene carriers highlight the dramatic influence that minute architectural modifications exert on nucleic acid complex formation and, consequently, on nanoparticle trafficking, cellular uptake, payload release and gene expression. ${ }^{14-16}$ However, the inherent polydispersity and random conformations of many of these formulations turn into a hurdle to assess structure-activity relationships (SAR) and optimize carrier performance. Alternatively, discrete molecular frameworks, allowing the installation of spatially segregated functional elements, have emerged as an appealing option. ${ }^{17}$ Thus, multifunctional pre-organized platforms, such as calixarenes, ${ }^{18}$ fullerenes,${ }^{19}$ pillar [5]arenes,${ }^{20}$ and cyclodextrins (CDs), ${ }^{21-23}$ have recently been exploited as scaffolds to build up monodisperse architectures with the ability to 
condense DNA into transfectious nanoparticles. Among them, CD-based vectors have been so far the most profusely investigated due to the inherent biocompatibility and the ease of chemical tailoring of the cyclooligosaccharide core. ${ }^{24,25}$

In the framework of a project aimed at engineering sitespecific gene vectors, ${ }^{26}$ we recently observed that installation of glycosyl antennae onto polycationic amphiphilic CDs (paCDs) did not only serve to mediate binding to specific receptors (lectins) on the target cells, ${ }^{27,28}$ but also dramatically influenced self-assembling capabilities in the presence of nucleic acids. It can be expected that DNA complexation by polycationic glycoamphiphilic CDs (pGaCDs) bearing aminoglycoside motifs will be particularly sensitive to structural modifications. Actually, the differential binding of aminoglycoside antibiotics to nucleic acids has already been exploited in the design of cationic lipidtype vectors. ${ }^{29-31}$ Moreover, a number of glycosylated gene carriers have been shown to operate with transfection efficiencies that correlated with their glyco-dependent self-assembling capabilities in the presence of nucleic acids rather than with specific recognition events towards target protein receptors. ${ }^{32}$ To gain a deeper insight into the structural features governing gene delivery efficiency of pGaCDs, herein we report the synthesis of a series of representatives featuring different aminoglucoside motifs, and the assessment of (i) their self-assembling ability in the presence of pDNA and (ii) the transfection efficiency of the resulting pGaCD-pDNA nanoaggregates (CDplexes) towards COS-7 cells. The results indicate that subtle variations in the topology of the cationic elements significantly impact the stability and physicochemical properties of the corresponding glycoCDplexes and, consequently, cell transfection efficiency and cytotoxicity profiles.

\section{Results and discussion}

\section{Design criteria and synthesis}

It has been previously shown that the number and arrangement of the cationic elements in paCDs critically influence gene carrier capabilities. ${ }^{33-36}$ To pinpoint these effects in the pGaCD series, three aminoglucosylated $\beta C D$ derivatives 2-4 (Fig. 1), featuring subtle differences in the disposition of the cationic elements but rather similar hydrophobic/hydrophilic balances, have been now considered. pGaCDs 2-4 also share the same spacer arm linking the aminoglucoside motif with the CD core. The thiourea functionalities have been purposely included in the molecular design since their presence has been previously shown to be beneficial for promoting reversible nucleic acid complexation through hydrogen bonding. ${ }^{37}$ Moreover, the thiourea-forming reaction has been proven to be extremely useful in "click-type" multiconjugation schemes. ${ }^{38,39}$ The pDNA complexing capabilities and transfection efficiencies of 2-4 have been evaluated in comparison with paCD 1, one of the most efficient cyclodextrin-based vector candidates reported to date. ${ }^{33}$

For the preparation of the differently-substituted pGaCDs 2-4 a convergent synthetic scheme was designed in which the key step is the coupling reaction of the heptaisothiocyanate $\mathbf{1 7}^{33}$

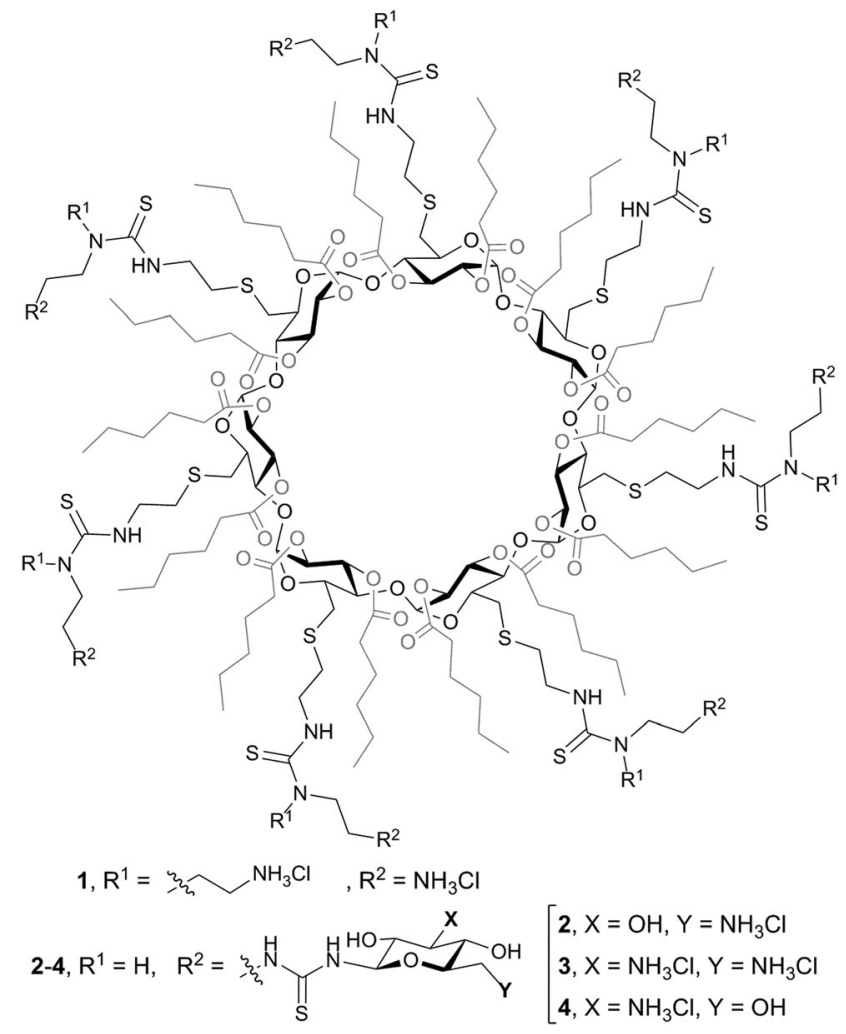

Fig. 1 Structure of paCD 1 and pGaCDs 2-4.

with a complementary amine-armed glycoconjugate (Scheme 1). For such purposes, the required isothiocyanates 5-7 were synthesized from the corresponding azidoglucosylenamine derivative following a previously described methodology. ${ }^{27,40}$ Isothiocyanate derivatives 5-7 were first coupled with $N$-tritylethylene-1,2diamine $^{41}(\rightarrow \mathbf{8 - 1 0})$, followed by sequential acetyl $(\rightarrow$ 11-13) and trityl cleavage to yield amines 14-16 (71-40\% over three steps, Scheme 1). Triethylamine-promoted nucleophilic addition of the resulting amine-armed aminoglucoside derivatives 14-16 to heptaisothiocyanate $17^{33}$ in DMF proceeds slowly at room temperature to furnish the fully substituted $\beta C D$ adducts 18-20. Final acid-promoted carbamate hydrolysis yielded the target heptavalent aminoglycoclusters 2-4, which were characterized as the corresponding perhydrochlorides (71-50\% overall, Scheme 1). The structure and molecular homogeneity of the CD-centred glycoclusters 18-20 and 2-4 were confirmed by NMR, MS and combustion analysis, the ensemble of data being consistent with the expected $C_{7}$-symmetry arrangement for homogeneously substituted $\beta \mathrm{CD}$ derivatives.

\section{Assessment of the self-assembling capabilities of pGaCDs 2-4}

The tendency of paCDs to form mixed nanoparticles upon formulation with nucleic acids (CDplexes) is a prerequisite to achieve efficient intracellular delivery and gene expression. ${ }^{25}$ The ability of pGaCDs $\mathbf{2 - 4}$ to form stable glycoCDplexes was first assessed by agarose gel electrophoresis at different nitrogen/phosphorous (N/P) ratios. ${ }^{42}$ Uncomplexed pDNA was used as a control. In order to avoid premature self-aggregation, 


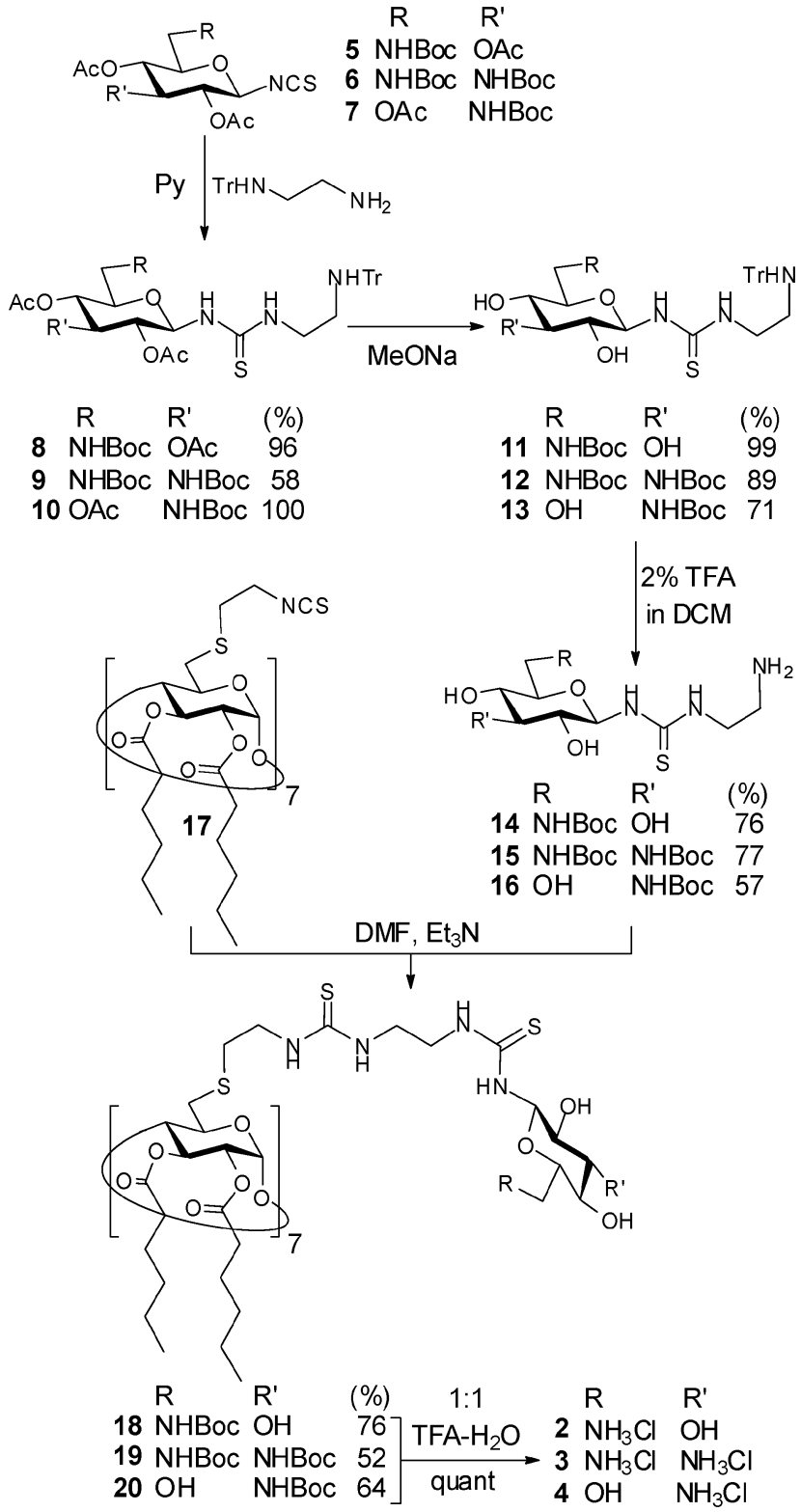

Scheme 1 Synthesis of pGaCDs $\mathbf{2 - 4}$

pGaCD stock solutions were prepared using DMSO and further diluted using the pDNA solution in HEPES buffer (final DMSO content never exceeded $1 \% \mathrm{v} / \mathrm{v}$, see Experimental section for details). All pGaCDs 2-4 retained the characteristic aggregation tendency of paCDs such as $\mathbf{1}$ in the presence of nucleic acids, though with remarkable differences. 6-Aminoglucosylated derivative 2 fully inhibited pDNA migration and prevented ethidium bromide intercalation at $\mathrm{N} / \mathrm{P} \geq 5$, indicating that pDNA in the complex is fully protected from the external environment under these conditions (Fig. 2A), paralleling that reported for paCD 1. ${ }^{33}$ On the other hand, its 3-aminoglucosylated congener 4 efficiently retarded pDNA migration but did not fully protect it from intercalation at the same $\mathrm{N} / \mathrm{P}$ ratios, indicating that the plasmid is, at least, partially accessible (Fig. 2B). Finally, the 14-cationic derivative 3 exhibited a significantly larger tendency

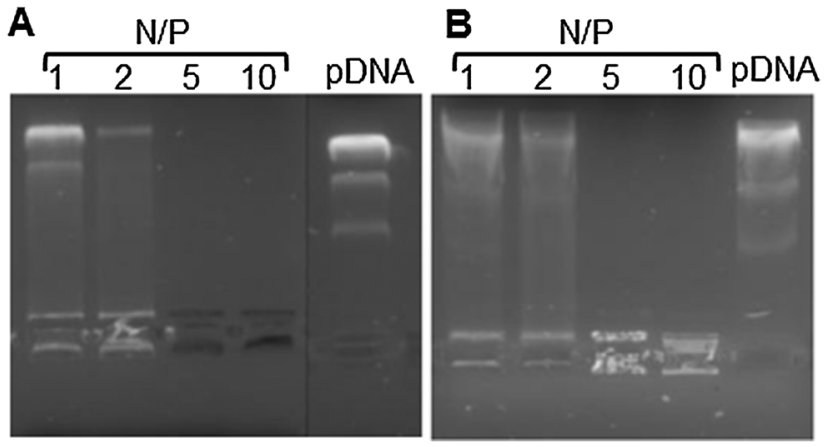

Fig. 2 Agarose gel electrophoresis shift assay of pGaCDs $\mathbf{2}$ (panel A) and $\mathbf{4}$ (panel B) at different N/P ratios. Naked pDNA (right lanes in each panel) is used for comparative purposes.

to self-aggregate upon dilution into the buffer solution, as seen by the appearance of a precipitate, thus preventing electrophoretic analysis.

The physicochemical properties of pGaCD:pDNA complexes formulated with 2-4 at N/P 10 were further characterized by dynamic light scattering (DLS). Table 1 collects the corresponding nanoparticle average diameters and $\xi$-potentials. Both heptacationic pGaCDs $\mathbf{2}$ and $\mathbf{4}$ produced CDplexes slightly larger (about $100 \mathrm{~nm}$ ) and more heavily charged (+48 and $+54 \mathrm{mV}$ ) than those reported for paCD 1 (76 nm and $+46 \mathrm{mV}$, respectively), ${ }^{33}$ but still in the range of interest for gene delivery (about $100 \mathrm{~nm}$ ). Attempts to prepare the corresponding glycoCDplexes from the diaminoglucoside-coated pGaCD 3 failed, however. As previously observed during the electrophoretic experiments, turbidity was immediately observed after addition of the aqueous buffer. DLS measurements revealed the presence of relatively large aggregates with a high polydispersity index and negative $\xi$-potential $(-12.0 \mathrm{mV})$. These results suggest that the larger tendency to self-aggregate 3 prevents its hierarchical arrangement around pDNA, irreversibly rendering polydisperse particles. An appropriate hydrophobic/hydrophilic balance seems to be therefore critical in order to trigger reversible interactions with pDNA leading to a well-ordered self-assembly.

The morphology of the glycoCDplexes was next evaluated by transmission electron microscopy (TEM). The corresponding micrographs confirmed the small size and homogeneous distribution of the nanoparticles obtained from pGaCDs 2 and 4

Table 1 Size (av. hydrodynamic diameter, $\mathrm{nm}$ ), polydispersity index (P. I.) and $\xi$-potential $(\mathrm{mV})$ of CDplexes of paCDs 1-4 and pDNA formulated at N/P 10 determined by DLS and M3-PALS analysis, respectively, in the absence and in the presence of serum

\begin{tabular}{|c|c|c|c|}
\hline Complex & Av. size $(\mathrm{nm})$ & P. I. & $\xi$-potential $(\mathrm{mV})$ \\
\hline 1:pDNA & $76 \pm 1$ & 0.12 & $+46 \pm 1$ \\
\hline 1:pDNA ${ }^{a}$ & $160 \pm 15$ & 0.13 & n.d. \\
\hline 2:pDNA & $100 \pm 20$ & 0.16 & $+48 \pm 1$ \\
\hline 2:pDNA ${ }^{a}$ & $240 \pm 20$ & 0.20 & n.d. \\
\hline 3:pDNA & $260 \pm 100$ & 0.50 & $-12 \pm 1$ \\
\hline 4:pDNA & $105 \pm 7$ & 0.17 & $+54 \pm 2$ \\
\hline 4:pDNA ${ }^{a}$ & $270 \pm 25$ & 0.22 & n.d. \\
\hline
\end{tabular}

\footnotetext{
${ }^{a}$ Measurements in the presence of serum (10\%).
} 


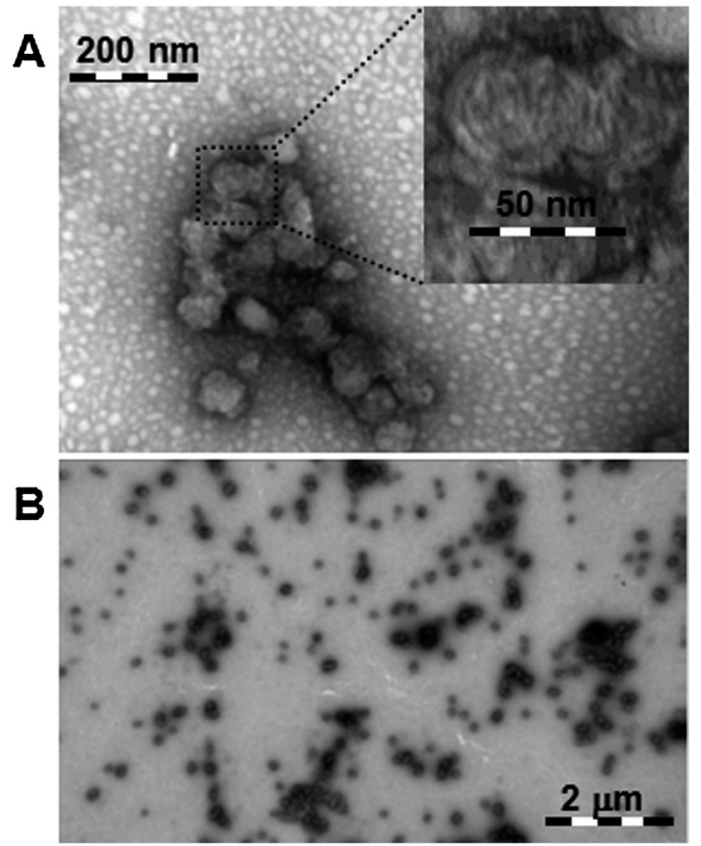

Fig. 3 TEM micrograph of (A) 2:pDNA and (B) 4:pDNA glycoCDplexes: the inset in panel $A$ represents the amplification of the structure of the particles.

(Fig. 3). A snail-like ultra-thin structure alternating dark (high electron density) and light (low electron density) regions could be observed in some cases, suggesting the arrangement of the pGaCD molecules in bilayers in the confined space between pDNA segments. A similar topography has been previously observed for transfectious CDplexes. ${ }^{27,33}$ As expected, formulations with derivative 3 did not render well-defined particles, but rather polydisperse aggregates.

\section{In vitro pDNA transfection into COS-7 cells}

The transfection efficiency of the self-assembled pGaCD:pDNA nanocomplexes formulated with 2 and 4 at N/P 5 and 10 was evaluated using a luciferase-encoding reporter gene (pTG11236, pCMV-SV40-luciferase-SV40pA) in monkey fibroblast-like COS-7 cells in HEPES buffer (20 mM, pH 7.4, see Experimental section for details) both in the absence and in the presence of serum. Linear Jet-PEI (22 kDa, polyplexes formulated at N/P 10) as well as paCD 1 (CDplexes formulated at N/P 5 and 10) and naked pDNA were used as positive and negative controls, respectively.

At N/P 5, pGaCDs 2-4 did not improve the expression of luciferase achieved with naked pDNA, neither in the absence nor in the presence of serum (Fig. 4). In the absence of serum, formulations at N/P 10 of the heptacationic pGaCDs 2 and 4 enhanced transfection efficiency by 4 and 2 orders of magnitude, respectively, implying that the corresponding nanoparticles are internalized to a significant extent through routes that allow endosome escape, DNA release and protein expression. Indeed, previous studies on structurally-related paCDs have shown that CDplexes are rapidly internalised in cells by several endocytic routes $^{43}$ and the reversibility of the paCD-pDNA association. ${ }^{44}$ Remarkably, the luciferase expression efficiency achieved with
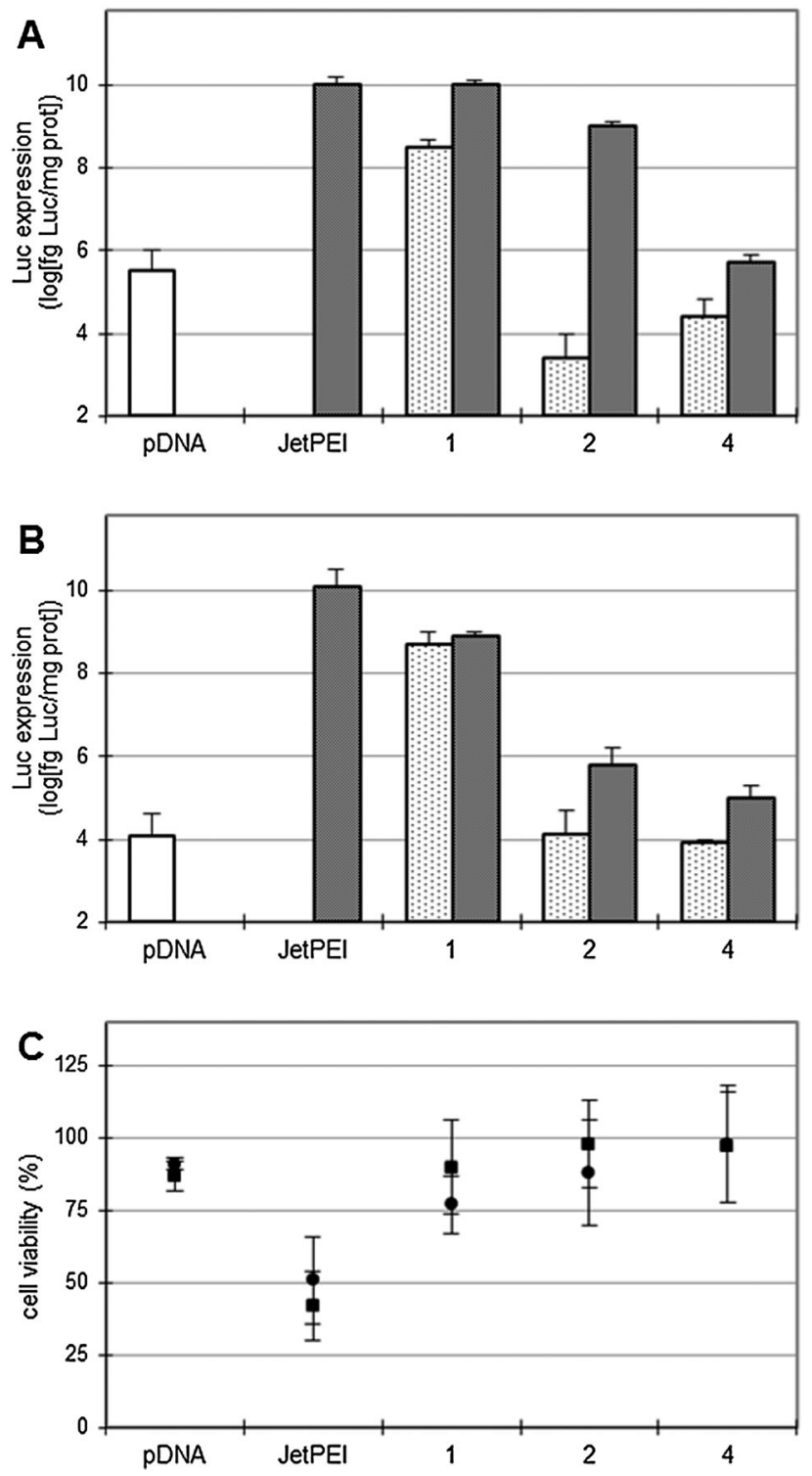

Fig. 4 In vitro transfection efficiency (bars) at N/P 5 (dotted bars) and 10 (filled bars) in COS-7 cells for CDplexes formulated with paCD 1 and pGaCDs $\mathbf{2}$ and $\mathbf{4}$ in the absence (panel A) and in the presence (panel B) of serum (10\%). Naked pDNA and Jet-PEI-based polyplexes (formulated at N/P 10) were used as negative and positive controls, respectively. Cell viability in the absence $(\mathbf{)})$ and in the presence $(\mathbf{\square})$ of serum $(10 \%)$ is represented in panel $\mathrm{C}$.

2:pDNA glycoCDplexes is only one order of magnitude lower than that determined for paCD 1 and Jet-PEI, with a much more favourable toxicity profile than the latter (Fig. 4, panel C). The large discrepancies between the performances at N/P 10 of pGaCDs 2 and 4, featuring similar hydrophilic/hydrophobic balances ( 7 protonable amino groups in each glucose antenna and 14 hexanoyl groups at secondary positions of $\beta C D$ ), reveal the dramatic influence exerted by the presentation mode of the protonable amine centers. The presence of the amino group at the primary position of the glucopyranose moiety probably favours the accessibility of the charged groups in the polycationic cluster to phosphate anions in the pDNA skeleton. A similar effect 
has been observed in cationic lipids furnished with aminoglycoside polar heads. ${ }^{29}$

The presence of serum $(10 \%)$ led to a generalized efficiency drop for both pGaCDs 2 and 4 when compared to paCD 1 . Probably, the greater increase in size of the glycoCDplexes formed using $\mathbf{2}$ and $\mathbf{4}$ after interaction with serum proteins is at the origin of this observation. Indeed, DLS measurements in serum-containing media (Table 1) support this hypothesis. Such phenomena probably result in weakening of the interaction with cell membrane components, thus limiting the efficient internalization process of nanoparticles and/or causing less favourable cellular trafficking.

CDplexes formulated with pGaCD 3 were unable to promote pDNA expression under identical experimental conditions either in the absence or in the presence of serum. Although improved pDNA binding has been associated with higher cationic valencies for cationic CDs, ${ }^{45}$ our results confirm that in the case of amphiphilic derivatives architectural features governing the self-assembling properties exert a much larger influence on the gene delivery capabilities. ${ }^{33,35,46}$

\section{Conclusions}

In summary, the assessment of the self-assembling and gene transfer capabilities of this set of polycationic glycoamphiphilic $\beta C D$ clusters illustrates the utmost relevance of structureactivity relationship analyses in the design of non-viral gene carriers. Small differences in the arrangement and display of the cationic elements responsible for the initial interaction of individual molecules with nucleic acid (pDNA) may have strong consequences in the transfection capabilities of the resulting nanocomplexes. All three pGaCDs clusters 2-4, similar to the previously reported non-glycosylated paCD 1 , are heavily cationic discrete species. Yet, while 2 and 4 render homogenous nanoparticles (glycoCDplexes) with cell transfection abilities, pGaCD 3 does not. Moreover, remarkable performance disparities are found for glycoCDplexes formulated with 2 and 4 in COS-7 cells, with 2:pDNA glycoCDplexes paralleling the golden standard Jet-PEI with null cytotoxicity. Altogether the present results illustrate the usefulness of well-defined molecular vectors for mapping the structural requirements governing DNA complexation and delivery. The information thus obtained, in combination with robust synthetic methodologies, can be put forward in the optimization of the vector architecture.

\section{Experimental}

\section{General methods}

All chemicals were obtained from Sigma-Aldrich (Germany) and Panreac (Spain) and were of analytical grade. No further purification steps were performed unless indicated. All solvents were used as obtained from the commercial sources. Optical rotations were measured at room temperature in $1 \mathrm{~cm}$ or $1 \mathrm{dm}$ tubes on a Jasco P-2000 polarimeter. Ultraviolet-visible (UV) spectra were recorded in $1 \mathrm{~cm}$ tubes on a Beckman DU640 UV spectrophotometer. Infrared (IR) spectra were recorded on a Jasco FT/IR 6000-Series spectrophotometer and are reported in reciprocal centimetres $\left(\mathrm{cm}^{-1}\right)$. ${ }^{1} \mathrm{H}$ (and ${ }^{13} \mathrm{C}$ NMR) spectra were recorded at 500 (125.7) and 400 (100.6) MHz using Bruker 500 and 400DRX instruments. Satisfactory resolutions were achieved after heating above $313 \mathrm{~K}$. 1D TOCSY, 2D COSY, HMQC and HSQC experiments were used to assist in the assignment of NMR spectra. Thin-layer chromatography (TLC) was carried out on aluminium sheets coated with silica gel 60G F254 (E. Merck), with visualization by UV light and by charring with $10 \% \mathrm{H}_{2} \mathrm{SO}_{4}$. Column chromatography was carried out on Silica Gel 60 (E. Merck, 230-400 mesh). FAB mass spectra were recorded using a Kratos MS-80 RFA instrument. The operating conditions were as follows: the primary beam consisted of Xe atoms with a maximum energy of $8 \mathrm{keV}$; the samples were dissolved in thioglycerol, and the positive ions were separated and accelerated over a potential of $7 \mathrm{keV}$; NaI was added as a cationizing agent. ESI mass spectra were recorded in the positive ion mode on a Bruker Esquire 6000 ion-trap mass spectrometer. Typically, samples were dissolved in appropriate solvents at low $\mu \mathrm{M}$ concentrations. Samples were introduced by direct infusion, using a Cole-Palmer syringe at a flow rate of $2 \mu \mathrm{L} \min ^{-1}$. Ions were scanned between 300 and $6000 \mathrm{Da}$ with a scan speed of $13000 \mathrm{Da} \mathrm{s}^{-1}$ at unit resolution using resonance ejection at the multipole resonance of one-third of the radio frequency $(\Omega=781.25 \mathrm{kHz})$. Elemental analyses were performed at the Instituto de Investigaciones Quimicas (Sevilla, Spain). paCD 1 was prepared according to the reported procedure. ${ }^{33}$ The starting materials 2,3,4-tri-O-acetyl-6- $N$-tert-butoxycarbonylamino-3-deoxy- $\beta$-D-glucopyranosyl isothiocyanate (5), ${ }^{27}$ 2,4-di-O-acetyl-3,6-di- $N$-tert-butoxycarbonylamino-3,6-dideoxy- $\beta$ D-glucopyranosyl isothiocyanate (6), ${ }^{40} 2,4,6$-tri-O-acetyl-3- $N$-tertbutoxycarbonylamino-3-deoxy- $\beta$-D-glucopyranosyl isothiocyanate (7), ${ }^{40} N$-tritylethylene-1,2-diamine, ${ }^{41}$ and heptakis[6-deoxy-2,3-di$O$-hexanoyl-6-(2-isothiocyanatoethylthio)]cyclomaltoheptaose $(\mathbf{1 7})^{33}$ were prepared as described previously.

\section{Syntheses}

$N^{\prime}$-(N-Trityl-2-aminoethyl)-N-(2,3,4-tri-O-acetyl-6-tert-butoxycarbonylamino-6-deoxy- $\beta$-D-glucopyranosyl)thiourea (8). To a solution of $N$-tritylethylene-1,2-diamine ${ }^{41}(0.50 \mathrm{~g}, 1.65 \mathrm{mmol})$ in pyridine $(20 \mathrm{~mL}) 5$ was added ${ }^{27}(0.49 \mathrm{~g}, 1.10 \mathrm{mmol})$ and the reaction mixture was stirred at $\mathrm{rt}$ for $15 \mathrm{~min}$, then concentrated. The solvent was eliminated and pyridine traces were eliminated by co-evaporation with toluene. The residue was purified by column chromatography $(1: 1$ EtOAc-petroleum ether). Yield: $0.79 \mathrm{~g}(96 \%) ; R_{\mathrm{f}}=0.40$ (1:1 EtOAc-petroleum ether); $[\alpha]_{\mathrm{D}}=-5.4$ (c 1.0, DCM); ${ }^{1} \mathrm{H}$ NMR $\left(500 \mathrm{MHz}, \mathrm{CDCl}_{3}\right): \delta=9.09(\mathrm{bs}, 2 \mathrm{H}$, NHCS), 7.41-7.17 (m, 15H, Ph), 6.63 (bs, 1H, NHTr), 5.62 (t, 1H, $\left.J_{1, \mathrm{NH}}=J_{1,2}=9.0 \mathrm{~Hz}, \mathrm{H}-1\right), 5.34\left(\mathrm{t}, 1 \mathrm{H}, J_{2,3}=J_{3,4}=9.0 \mathrm{~Hz}, \mathrm{H}-3\right)$, 4.98 (t, 1H, H-2), 4.80 (bs, 1H, H-4), 4.57 (bs, 1H, NH-6), 3.69 (bs, 1H, H-5), 3.34 (bs, 1H, H-6a), 3.14 (bs, 1H, H-6b), 2.56 (m, $2 \mathrm{H}, \mathrm{CH}_{2} \mathrm{NHCS}$ ), $2.44\left(\mathrm{~m}, 2 \mathrm{H}, \mathrm{CH}_{2} \mathrm{NHTr}\right), 2.06,2.05(3 \mathrm{~s}, 9 \mathrm{H}$, $\mathrm{MeCO}), 1.41$ (s, 9H, $\left.\mathrm{CMe}_{3}\right) ;{ }^{13} \mathrm{C} \mathrm{NMR}\left(100.6 \mathrm{MHz}, 313 \mathrm{~K}, \mathrm{CDCl}_{3}\right)$ : $\delta=184.6$ (CS), 171.5, 171.0, 169.7 (3 CO ester), 155.7 (CO carbamate), 145.1-126.9 (Ph), $88.3(\mathrm{C}-1), 79.5\left(\mathrm{CMe}_{3}\right), 74.3$ 
(C-3), $72.9\left(\mathrm{C}-5, \mathrm{CPh}_{3}\right), 71.4$ (C-2), 69.3 (C-4), 60.3 (C-6), 45.3 ( $\left.\mathrm{CH}_{2} \mathrm{NHCS}\right), 40.8$ ( $\left.\mathrm{CH}_{2} \mathrm{NHTr}\right), 28.3\left(\mathrm{CMe}_{3}\right), 20.9,20.6,20.5$ (3 MeCO); ESIMS: $m / z 771[\mathrm{M}+\mathrm{Na}]^{+}$; anal. calcd for $\mathrm{C}_{39} \mathrm{H}_{48} \mathrm{~N}_{4} \mathrm{O}_{19} \mathrm{~S}: \mathrm{C}, 62.55 ; \mathrm{H}, 6.46 ; \mathrm{N}, 7.48$. Found: C, 62.71; H, 6.39; N, 7.33.

$N^{\prime}$-( $N$-Trityl-2-aminoethyl)- $N$-(2,4-di-O-acetyl-3,6-di-tert-butoxycarbonylamino-3,6-dideoxy- $\beta$-D-glucopyranosyl)thiourea (9). To a solution of $6^{40}(0.12 \mathrm{~g}, 0.24 \mathrm{mmol})$ in dry pyridine $(4 \mathrm{~mL}), N$-trityl1,2-ethylenediamine ${ }^{41}(0.11 \mathrm{~g}, 0.36 \mathrm{mmol}, 1.5 \mathrm{eq}$.) was added and the reaction mixture was stirred at $\mathrm{rt}$ for $1 \mathrm{~h}$. The solvent was evaporated under reduced pressure and traces of pyridine were removed by co-evaporation with toluene. The residue was purified by flash column chromatography $(2: 3 \rightarrow 1: 1$ EtOAc-petroleum ether) to give 11. Yield: $114 \mathrm{mg}(58 \%)$; $R_{\mathrm{f}}=0.66$ (1:1 EtOAc-petroleum ether); $[\alpha]_{\mathrm{D}}=-1.17$ (c 1.0, $\mathrm{MeOH}) ; \mathrm{UV}(\mathrm{MeOH}): \lambda_{\max }=246,216 \mathrm{~nm}\left(\varepsilon_{\mathrm{mM}} 10.1,26.1\right)$; IR $(\mathrm{NaCl}): \nu_{\max }=3350,2975,1746,1224,1034,706 \mathrm{~cm}^{-1} ;{ }^{1} \mathrm{H} \mathrm{NMR}$ $\left(400 \mathrm{MHz}, \mathrm{CD}_{3} \mathrm{OD}, 323 \mathrm{~K}\right): \delta=7.44(\mathrm{~m}, 15 \mathrm{H}, \mathrm{Ph}), 5.72(\mathrm{~d}, 1 \mathrm{H}$, $\left.J_{1,2}=9.3 \mathrm{~Hz}, \mathrm{H}-1\right), 4.99(\mathrm{~m}, 1 \mathrm{H}, \mathrm{H}-2), 4.89$ (m, 1H, H-4), 3.90 (m, $1 \mathrm{H}, \mathrm{H}-3), 3.70\left(\mathrm{~m}, 3 \mathrm{H}, \mathrm{CH}_{2} \mathrm{NHCS}, \mathrm{H}-5\right), 3.32\left(\mathrm{dd}, J_{6 \mathrm{a}, 6 \mathrm{~b}}=14.6 \mathrm{~Hz}\right.$, $\left.J_{5,6 \mathrm{a}}=2.7 \mathrm{~Hz}, \mathrm{H}-6 \mathrm{a}\right), 3.15$ (dd, $\left.J_{5,6 \mathrm{a}}=6.0 \mathrm{~Hz}, \mathrm{H}-6 \mathrm{~b}\right), 2.43(\mathrm{~m}, 2 \mathrm{H}$, $\mathrm{CH}_{2} \mathrm{NHTr}$ ), 2.09, 1.95 (2s, 6H, MeCO), 1.43 (s, 18H, $\mathrm{CMe}_{3}$ ); ${ }^{13} \mathrm{C} \mathrm{NMR}$ (100.6 MHz, $\left.\mathrm{CD}_{3} \mathrm{OD}, 313 \mathrm{~K}\right): \delta=186.0$ (CS), 172.0, 171.6 (CO ester), 158.1, 157.9 (CO carbamate), 147.2-127.4 (Ph), 84.3 (C-1), 80.5 (2 $\mathrm{CMe}_{3}$ ), $80.4\left(\mathrm{CPh}_{3}\right), 76.9$ (C-5), 72.3 (C-2), 71.0 (C-4), 57.1 (C-3), $45.9\left(\mathrm{CH}_{2} \mathrm{NHCS}\right), 44.6\left(\mathrm{CH}_{2} \mathrm{NHTr}\right), 42.5(\mathrm{C}-6), 28.8,28.7$ (2 $\left.\mathrm{CMe}_{3}\right)$, 20.8, 20.7 (2 MeCO); FABMS: $m / z=828\left([\mathrm{M}+\mathrm{Na}]^{+}\right)$; anal. calcd for $\mathrm{C}_{42} \mathrm{H}_{55} \mathrm{~N}_{5} \mathrm{O}_{9} \mathrm{~S}: \mathrm{C}, 62.59 ; \mathrm{H}, 6.88 ; \mathrm{N}, 8.69$. Found: C, 62.33; H, $6.61 ; \mathrm{N}, 8.51$.

$N^{\prime}$-( $N$-Trityl-2-aminoethyl)- $N$-(2,4,6-tri- $O$-acetyl-3-tert-butoxycarbonylamino-3-deoxy- $\beta$-D-glucopyranosyl)thiourea (10). To a solution of $7^{40}(0.156 \mathrm{~g}, 0.35 \mathrm{mmol})$ in dry pyridine $(6.4 \mathrm{~mL})$, $N$-trityl-1,2-ethylenediamine ${ }^{41}(0.16 \mathrm{~g}, 0.53 \mathrm{mmol})$ was added and the reaction mixture was stirred at $\mathrm{rt}$ for $1 \mathrm{~h}$. The solvent was eliminated under reduced pressure and traces of pyridine were removed by co-evaporation with toluene. The residue was purified by column chromatography $(2: 1$ EtOAc-petroleum ether) to give 10. Yield: $0.27 \mathrm{~g}$ (quantitative); $R_{\mathrm{f}}=0.51(1: 1$ EtOAc-petroleum ether); $[\alpha]_{\mathrm{D}}=-3.6$ (c 1.0, DCM); UV (DCM): $\lambda_{\text {max }}=255,226 \mathrm{~nm}\left(\varepsilon_{\mathrm{mM}} 16.0,19.5\right) ; \mathrm{IR}(\mathrm{NaCl}): \nu_{\max }=3351$, 3048, 2977, 1746, 1227, 1037, 741, $708 \mathrm{~cm}^{-1}$; ${ }^{1} \mathrm{H}$ NMR $(500 \mathrm{MHz}$, $\left.\mathrm{CD}_{3} \mathrm{OD}, 323 \mathrm{~K}\right): \delta=7.46(\mathrm{~m}, 15 \mathrm{H}, \mathrm{Ph}), 5.78\left(\mathrm{~d}, 1 \mathrm{H}, J_{1,2}=9.5 \mathrm{~Hz}\right.$, $\mathrm{H}-1), 5.01$ (bs, $2 \mathrm{H}, \mathrm{H}-2, \mathrm{H}-4), 4.25\left(\mathrm{dd}, 1 \mathrm{H}, J_{6 \mathrm{a}, 6 \mathrm{~b}}=12.5 \mathrm{~Hz}, J_{5,6 \mathrm{a}}=\right.$ $5.0 \mathrm{~Hz}, \mathrm{H}-6 \mathrm{a}$ ), 4.10 (dd, $\left.1 \mathrm{H}, J_{5,6 \mathrm{~b}}=6.0 \mathrm{~Hz}, \mathrm{H}-6 \mathrm{~b}\right), 3.93(\mathrm{~m}, 1 \mathrm{H}$, $\mathrm{H}-3), 3.86$ (m, 1H, H-5), 3.71 (m, 2H, $\left.\mathrm{CH}_{2} \mathrm{NHCS}\right), 2.38(\mathrm{~m}, 2 \mathrm{H}$, $\mathrm{CH}_{2} \mathrm{NHTr}$ ), 2.06, 2.05, 1.97 (3 s, 9H, MeCO), 1.46 (s, 9H, $\mathrm{CMe}_{3}$ ); ${ }^{13} \mathrm{C}$ NMR (125.7 MHz, $\left.\mathrm{CD}_{3} \mathrm{OD}, 323 \mathrm{~K}\right): \delta=186.0$ (CS), 172.4, 172.1, 171.5 (CO ester), 157.9 (CO carbamate), 147.3-127.3 (Ph), 84.6 (C-1), $80.6\left(\mathrm{CMe}_{3}\right), 79.5\left(\mathrm{CPh}_{3}\right), 75.8(\mathrm{C}-5), 72.3(\mathrm{C}-2), 70.2$ (C-4), 63.6 (C-6), 57.1 (C-3), 46.0 ( $\left.\mathrm{CH}_{2} \mathrm{NHCS}\right), 44.7\left(\mathrm{CH}_{2} \mathrm{NHTr}\right)$, $28.7\left(\mathrm{CMe}_{3}\right), 20.7,20.6$ (3 MeCO); FABMS: $m / z=771\left([\mathrm{M}+\mathrm{Na}]^{+}\right)$; anal. calcd for $\mathrm{C}_{39} \mathrm{H}_{48} \mathrm{~N}_{4} \mathrm{O}_{9} \mathrm{~S}: \mathrm{C}, 48.97 ; \mathrm{H}, 6.58 ; \mathrm{N}$, 8.57. Found: C, 62.41; H, 6.329; N, 7.37.

$N^{\prime}$-( $N$-Trityl-2-aminoethyl)- $N$-(6-tert-butoxycarbonylamino-6deoxy- $\boldsymbol{\beta}$-D-glucopyranosyl)thiourea (11). Compound 11 was quantitatively obtained by treatment of 8 (0.76 g, $1.02 \mathrm{mmol})$ with methanolic MeONa ( $0.5 \mathrm{~mol}$ per mol of acetates) in $\mathrm{MeOH}$ $(10 \mathrm{~mL})$ at $0{ }^{\circ} \mathrm{C}$ followed by neutralization with Amberlite $120\left(\mathrm{H}^{+}\right)$. Yield: $0.64 \mathrm{~g} ; R_{\mathrm{f}}=0.62\left(45: 5: 3\right.$ EtOAc-EtOH- $\left.\mathrm{H}_{2} \mathrm{O}\right)$; $[\alpha]_{\mathrm{D}}=-11.2(c 1.0, \mathrm{MeOH}) ;{ }^{1} \mathrm{H}$ NMR (400 MHz, MeOD, $\left.313 \mathrm{~K}\right)$ : $\delta=7.45-7.14(\mathrm{~m}, 15 \mathrm{H}, \mathrm{Ph}), 5.22$ (bs, 1H, H-1), 3.66 (bs, 2H, $\mathrm{CH}_{2} \mathrm{NHCS}$ ), 3.48 (bd, $\left.1 \mathrm{H}, J_{6 \mathrm{a}, 6 \mathrm{~b}}=13.6 \mathrm{~Hz}, \mathrm{H}-6 \mathrm{a}\right), 3.41(\mathrm{t}, 1 \mathrm{H}$, $\left.J_{2,3}=J_{3,4}=9.5 \mathrm{~Hz}, \mathrm{H}-3\right), 3.33\left(\mathrm{ddd}, 1 \mathrm{H}, J_{4,5}=9.1 \mathrm{~Hz}, J_{5,6 \mathrm{~b}}=7.0 \mathrm{~Hz}\right.$, $\left.J_{5,6 \mathrm{a}}=2.7 \mathrm{~Hz}, \mathrm{H}-5\right), 3.27$ (bt, 1H, H-2), 3.15 (m, 1H, H-6b), 3.14 (dd, 1H, H-4), 4.57 (bs, 1H, NH-6), 2.37 (m, 2H, $\mathrm{CH}_{2} \mathrm{NHTr}$ ), 1.40 (s, 9H, $\mathrm{CMe}_{3}$ ); ${ }^{13} \mathrm{C}$ NMR (100.6 MHz, MeOD, $\left.313 \mathrm{~K}\right): \delta=185.7$ (CS), 158.7 (CO carbamate), 147.3-127.4 (Ph), 85.2 (C-1), 80.4 $\left(C \mathrm{Me}_{3}\right), 78.7$ (C-3), 77.7 (C-5), 74.4 (C-2), $72.9(\mathrm{C}-4), 72.2\left(\mathrm{CPh}_{3}\right)$, 46.1 ( $\left.\mathrm{CH}_{2} \mathrm{NHCS}\right), 44.7\left(\mathrm{CH}_{2} \mathrm{NHTr}\right), 42.9$ (C-6), 28.8 (CMe 3 ); ESIMS: $m / z 645[\mathrm{M}+\mathrm{Na}]^{+}$; anal. calcd for $\mathrm{C}_{33} \mathrm{H}_{42} \mathrm{~N}_{4} \mathrm{O}_{6} \mathrm{~S}$ : C, 63.64; H, 6.80; N, 9.00; found: C, 63.62; H, 6.64; N, 8.78.

$N^{\prime}$-( $N$-Trityl-2-aminoethyl)- $N$-(3,6-di-tert-butoxycarbonylamino3,6-dideoxy- $\beta$-D-glucopyranosyl) thiourea (12). Compound 12 was obtained by treatment of 9 ( $89 \mathrm{mg}, 0.11 \mathrm{mmol})$ with methanolic MeONa (0.5 mol per mol of acetates) in $\mathrm{MeOH}(10 \mathrm{~mL})$ at $0{ }^{\circ} \mathrm{C}$. The crude product was purified by column chromatography $(22: 1$ DCM-MeOH). Yield: $71 \mathrm{mg}(89 \%) ; R_{\mathrm{f}}=0.67$ (22:1 DCM-MeOH); $[\alpha]_{\mathrm{D}}=-5.2(c 1.0, \mathrm{MeOH}) ; \mathrm{UV}(\mathrm{MeOH}): \lambda_{\max }=243,214 \mathrm{~nm}$ $\left(\varepsilon_{\mathrm{mM}} 17.4,42.2\right)$; IR $(\mathrm{KBr}): \nu_{\max }=3412,3063,2973,1685,1250$, 1079, $706 \mathrm{~cm}^{-1}$; ${ }^{1} \mathrm{H}$ NMR (500 MHz, $\left.\mathrm{CD}_{3} \mathrm{OD}, 313 \mathrm{~K}\right): \delta=7.36$ (m, 15H, Ph), 5.21 (bs 1H, H-1), 3.66 (m, 2H, CH $\mathrm{H}_{2} \mathrm{NHCS}$ ), 3.49 $\left(\mathrm{dd}, J_{6 \mathrm{a}, 6 \mathrm{~b}}=13.7 \mathrm{~Hz}, J_{5,6 \mathrm{a}}=2.6 \mathrm{~Hz}, \mathrm{H}-6 \mathrm{a}\right), 3.41\left(\mathrm{~d}, J_{2,3}=J_{3,4}=9.5 \mathrm{~Hz}\right.$, $1 \mathrm{H}, \mathrm{H}-3), 3.38\left(\mathrm{~m}, 3 \mathrm{H}, J_{4,5}=9.5 \mathrm{~Hz}, J_{5,6 \mathrm{~b}}=6.5 \mathrm{~Hz}, \mathrm{H}-5\right), 3.34$ $\left(\mathrm{m}, 1 \mathrm{H}, J_{1,2}=9.5 \mathrm{~Hz}, \mathrm{H}-2\right), 3.14(\mathrm{dd}, 1 \mathrm{H}, \mathrm{H}-6 \mathrm{~b}), 2.43(\mathrm{~m}, 2 \mathrm{H}$, $\left.\mathrm{CH}_{2} \mathrm{NHTr}\right) 1.43$ (s, $18 \mathrm{H}, \mathrm{CMe}_{3}$ ); ${ }^{13} \mathrm{C} \mathrm{NMR}$ (125.7 MHz, $\mathrm{CD}_{3} \mathrm{OD}$, $313 \mathrm{~K}): \delta=186.0$ (CS), 159.2, 158.6 (CO carbamate), 147.4-127.4 (Ph), 86.3 (C-1), 80.6 (2 $\left.\mathrm{CMe}_{3}\right), 79.0$ (C-5), $72.8(\mathrm{C}-2), 72.3\left(\mathrm{CPh}_{3}\right)$, 71.3 (C-4), 61.8 (C-3), $46.2\left(\mathrm{CH}_{2} \mathrm{NHCS}\right), 44.8\left(\mathrm{CH}_{2} \mathrm{NHTr}\right), 43.2$ (C-6), $28.4\left(2 \mathrm{CMe}_{3}\right)$; FABMS: $m / z=745\left([\mathrm{M}+\mathrm{Na}]^{+}\right)$; anal. calcd for $\mathrm{C}_{38} \mathrm{H}_{51} \mathrm{~N}_{5} \mathrm{O}_{7} \mathrm{~S}$ : C, 63.22; H, 7.12; N, 9.70. Found: C, 62.94; H, 7.00; $\mathrm{N}, 9.59$.

$N^{\prime}$-( $N$-Trityl-2-aminoethyl)- $N$-(3-tert-butoxycarbonylamino-3deoxy- $\beta$-D-glucopyranosyl)thiourea (13). Compound 13 was obtained by treatment of $\mathbf{1 0}(0.21 \mathrm{~g}, 0.28 \mathrm{mmol})$ with methanolic MeONa ( $0.5 \mathrm{~mol}$ per mol of acetates) in $\mathrm{MeOH}(3 \mathrm{~mL})$ at $0{ }^{\circ} \mathrm{C}$. The reaction mixture was stirred at $\mathrm{rt}$ for $35 \mathrm{~min}$. The crude product was purified by column chromatography $6: 1$ EtOAc-petroleum ether $\rightarrow$ EtOAc). Yield: $127 \mathrm{mg}(71 \%) ; R_{\mathrm{f}}=$ 0.43 (EtOAc); $[\alpha]_{\mathrm{D}}=-7.3$ (c 1.0, DCM); UV (DCM): $\lambda_{\max }=254$, $228 \mathrm{~nm}\left(\varepsilon_{\mathrm{mM}} 15.3,18.6\right)$; IR $(\mathrm{NaCl}): \nu_{\max }=3329,3083,2929$, 1676, 1292, 1245, 1168, 1079, 1026, 748, $706 \mathrm{~cm}^{-1}$; ${ }^{1} \mathrm{H}$ NMR (500 MHz, $\mathrm{CD}_{3} \mathrm{OD}, 323 \mathrm{~K}$ ): $\delta=7.38(\mathrm{~m}, 15 \mathrm{H}, \mathrm{Ph}$ ), 5.23 (bs $1 \mathrm{H}$, $\mathrm{H}-1), 3.85$ (dd, $\left.1 \mathrm{H}, J_{6 \mathrm{a}, 6 \mathrm{~b}}=12.0 \mathrm{~Hz}, J_{5,6 \mathrm{a}}=2.5 \mathrm{~Hz}, \mathrm{H}-6 \mathrm{a}\right), 3.67$ (bs, $2 \mathrm{H}, \mathrm{CH}_{2} \mathrm{NHCS}$ ), 3.66 (dd, $\left.1 \mathrm{H}, J_{5,6 \mathrm{~b}}=5.0 \mathrm{~Hz}, \mathrm{H}-6 \mathrm{~b},\right), 3.48(\mathrm{t}, 1 \mathrm{H}$, $\left.J_{2,3}=J_{3,4}=10.0 \mathrm{~Hz}, \mathrm{H}-3\right), 3.44\left(\mathrm{ddd}, 1 \mathrm{H}, J_{4,5}=10.0 \mathrm{~Hz}, \mathrm{H}-5\right), 3.38$ (t, 1H, H-4), 3.43 (m, 1H, H-2), 2.41 (m, 2H, $\mathrm{CH}_{2} \mathrm{NHTr}$ ), 1.48 (s, $9 \mathrm{H}, \mathrm{CMe}_{3}$ ); ${ }^{13} \mathrm{C}$ NMR (125.7 MHz, $\left.\mathrm{CD}_{3} \mathrm{OD}, 323 \mathrm{~K}\right): \delta=186$ (CS), 159.2, (CO carbamate), 130.2-127.4 (Ph), 86.1 (C-1), 80.5 $\left(\mathrm{CMe}_{3}\right), 80.4$ (C-5), 72.8 (C-2), $72.2\left(\mathrm{CPh}_{3}\right), 70.0(\mathrm{C}-4), 62.9$ (C-6), 61.9 (C-3), 46.3 ( $\left.\mathrm{CH}_{2} \mathrm{NHCS}\right), 44.6\left(\mathrm{CH}_{2} \mathrm{NHTr}\right), 28.8\left(\mathrm{CMe}_{3}\right)$; FABMS: $m / z=646\left([\mathrm{M}+\mathrm{Na}]^{+}\right)$; anal. calcd for $\mathrm{C}_{33} \mathrm{H}_{42} \mathrm{~N}_{4} \mathrm{O}_{6} \mathrm{~S}: \mathrm{C}$, 63.64; H, 6.80; N, 9.00. Found: C, 63.51; H, 6.67; N, 8.85. 
$N^{\prime}$-(2-Aminoethyl)- $N$-(6-tert-butoxycarbonylamino-6-deoxy- $\beta$ D-glucopyranosyl)thiourea (14). Compound $12(0.2 \mathrm{~g}, 0.32 \mathrm{mmol})$ was treated with $2 \%$ TFA in DCM $(8 \mathrm{~mL})$ at rt for $4 \mathrm{~h}$. The organic phase was extracted with water $(6 \times 10 \mathrm{~mL})$, and the aqueous solution was neutralized, freeze-dried and then purified by column chromatography $\left(10: 1: 1 \mathrm{MeCN}-\mathrm{H}_{2} \mathrm{O}-\mathrm{NH}_{4} \mathrm{OH}\right)$. Yield: $88 \mathrm{mg}$ (76\%); $R_{\mathrm{f}}=0.08\left(10: 1: 1 \mathrm{MeCN}-\mathrm{H}_{2} \mathrm{O}-\mathrm{NH}_{4} \mathrm{OH}\right) ;[\alpha]_{\mathrm{D}}=$ -19.2 (c 1.0 in $\mathrm{H}_{2} \mathrm{O}$ ); ${ }^{1} \mathrm{H}$ NMR (400 MHz, $\mathrm{D}_{2} \mathrm{O}, 323 \mathrm{~K}$ ): $\delta=5.52$ (bs, $1 \mathrm{H}, \mathrm{H}-1), 3.89$ (bs, $\left.2 \mathrm{H}, \mathrm{CH}_{2} \mathrm{NHCS}\right), 3.78\left(\mathrm{t}, 1 \mathrm{H}, J_{2,3}=J_{3,4}=\right.$ $9.0 \mathrm{~Hz}, \mathrm{H}-3), 3.71$ (m, 2H, H-5, H-6a), 3.65 (t, 1H, $J_{1,2}=9.0 \mathrm{~Hz}$, $\mathrm{H}-2$ ), 3.51 (dd, $\left.1 \mathrm{H}, J_{3,4}=9.0 \mathrm{~Hz}, \mathrm{H}-4\right), 3.43\left(\mathrm{dd}, 1 \mathrm{H}, J_{5,6 \mathrm{~b}}=7.2 \mathrm{~Hz}\right.$, $\left.J_{6 \mathrm{a}, 6 \mathrm{~b}}=13.6 \mathrm{~Hz}, \mathrm{H}-6 \mathrm{~b}\right), 3.17$ (bt, $2 \mathrm{H},{ }^{3} \mathrm{~J}_{\mathrm{H}, \mathrm{H}}=6.0 \mathrm{~Hz}, \mathrm{CH}_{2} \mathrm{NH}_{2}$ ), 1.64 (s, 9H, $\mathrm{CMe}_{3}$ ); ${ }^{13} \mathrm{C}$ NMR (100.6 MHz, $\left.\mathrm{D}_{2} \mathrm{O}, 323 \mathrm{~K}\right): \delta=184.7$ (CS), 159.4 (CO carbamate), 85.5 (C-1), $82.4\left(\mathrm{CMe}_{3}\right), 77.7$ (C-3), 77.0 (C-5), 73.2 (C-2), 72.2 (C-4), 45.8 ( $\mathrm{CH}_{2} \mathrm{NHCS}$ ), 42.5 (C-6), 40.6 $\left(\mathrm{CH}_{2} \mathrm{NH}_{2}\right), 28.9\left(\mathrm{CMe}_{3}\right)$; ESIMS: $m / z 381\left[\mathrm{M}+\mathrm{H}^{+}\right]$; anal. calcd for $\mathrm{C}_{14} \mathrm{H}_{28} \mathrm{~N}_{4} \mathrm{O}_{6} \mathrm{~S} \cdot \mathrm{H}_{2} \mathrm{O}: \mathrm{C}, 42.20 ; \mathrm{H}, 7.59 ; \mathrm{N}, 14.06$; found: $\mathrm{C}, 41.93 ; \mathrm{H}$, $7.24 ; \mathrm{N}, 14.49$.

$N^{\prime}$-(2-Aminoethyl)- $N$-(3,6-di-tert-butoxycarbonylamino-3,6dideoxy- $\boldsymbol{\beta}$-D-glucopyranosyl)thiourea (15). Compound 12 (69 mg, $95 \mu \mathrm{mol})$ was treated with $2 \%$ TFA in DCM $(3 \mathrm{~mL})$ at rt for $5 \mathrm{~h}$. The organic phase was extracted with water $(6 \times 10 \mathrm{~mL})$, and the aqueous solution was neutralized (diluted $\mathrm{NH}_{4} \mathrm{OH}$ ) and freezedried to give 15. Yield: $35 \mathrm{mg}(77 \%) ; R_{\mathrm{f}}=0.43(10: 1: 1 \mathrm{MeCN}-$ $\left.\mathrm{H}_{2} \mathrm{O}-\mathrm{NH}_{4} \mathrm{OH}\right) ;[\alpha]_{\mathrm{D}}=+1.3\left(c \quad 0.8, \mathrm{H}_{2} \mathrm{O}\right) ; \mathrm{UV}\left(\mathrm{H}_{2} \mathrm{O}\right): 244 \mathrm{~nm}$ $\left(\varepsilon_{\mathrm{mM}}\right.$ 3.6); IR (KBr): $\nu_{\max }=3117,1668,1202,1137 \mathrm{~cm}^{-1}$; ${ }^{1} \mathrm{H}$ NMR (500 MHz, $12: 1 \mathrm{CD}_{3} \mathrm{OD}-\mathrm{D}_{2} \mathrm{O}, 323 \mathrm{~K}$ ): $\delta=5.34$ (bs, $1 \mathrm{H}, \mathrm{H}-1), 3.96\left(\mathrm{~m}, \mathrm{CH}_{2} \mathrm{NHCS}\right), 3.55\left(\mathrm{dd}, 2 \mathrm{H}, J_{6 \mathrm{a}, 6 \mathrm{~b}}=14.0 \mathrm{~Hz}, J_{5,6 \mathrm{a}}=\right.$ $2.5 \mathrm{~Hz}, \mathrm{H}-6 \mathrm{a}), 3.49$ (m, 3H, H-2, H-4, H-5), 3.29 (t, 1H, $J_{2,3}=J_{3,4}=$ $9.3 \mathrm{~Hz}, \mathrm{H}-3), 3.28\left(\mathrm{~m}, 2 \mathrm{H}, \mathrm{CH}_{2} \mathrm{NH}_{2}\right.$ ), 3.19 (dd, $1 \mathrm{H}, J_{5,6 \mathrm{~b}}=7.0 \mathrm{~Hz}$, $\mathrm{H}-6 \mathrm{~b}), 1.49$ (s, $18 \mathrm{H}, \mathrm{CMe}_{3}$ ); ${ }^{13} \mathrm{C} \mathrm{NMR}\left(125.7 \mathrm{MHz}, 12: 1 \mathrm{CD}_{3} \mathrm{OD}-\right.$ $\mathrm{D}_{2} \mathrm{O}, 323 \mathrm{~K}$ ): $\delta=186.5$ (CS), 159.2, 158.7 (CO carbamate), 86.0 (C-1), 80.9 (2 $\mathrm{CMe}_{3}$ ), 78.7 (C-5), 72.3 (C-2), 71.1 (C-4), 61.3 (C-3), 42.9 (C-6), $42.5\left(\mathrm{CH}_{2} \mathrm{NHCS}\right), 40.6\left(\mathrm{CH}_{2} \mathrm{NH}_{2}\right), 28.8$ (2 $\left.\mathrm{CMe}_{3}\right)$; ESIMS: $m / z=479.8\left[\mathrm{M}+\mathrm{H}^{+}\right]$; anal. calcd for $\mathrm{C}_{19} \mathrm{H}_{37} \mathrm{~N}_{5} \mathrm{O}_{7} \mathrm{~S}: \mathrm{C}$, 47.58; H, 7.78; N, 14.60. Found: C, 47.20; H, 7.45; N, 14.27.

$\boldsymbol{N}^{\prime}$-(2-Aminoethyl)- $\boldsymbol{N}$-(3-tert-butoxycarbonylamino-3-deoxy- $\beta$ D-glucopyranosyl)thiourea (16). Compound 13 (95 mg, $0.15 \mathrm{mmol}$ ) was treated with DCM-TFA $(1 \%, 4 \mathrm{~mL})$ at $\mathrm{rt}$ for $4 \mathrm{~h}$. The organic phase was extracted with water $(6 \times 10 \mathrm{~mL})$, and the aqueous solution was neutralized $\left(\mathrm{NH}_{4} \mathrm{OH}\right.$ aqueous) and freeze-dried to give 16. Yield: $57 \mathrm{mg}$ (quantitative); $R_{\mathrm{f}}=0.88$ (10:1:1 MeCN-H $\left.\mathrm{H}_{2} \mathrm{O}-\mathrm{NH}_{4} \mathrm{OH}\right) ;[\alpha]_{\mathrm{D}}=-108.1$ (c 1.0, $\left.\mathrm{MeOH}\right)$; UV (MeOH): 248, $212 \mathrm{~nm}\left(\varepsilon_{\mathrm{mM}} 10.8,9.0\right)$; IR (KBr): $\nu_{\max }=3300$, 3078, 2971, 1687, 1074, $1032 \mathrm{~cm}^{-1} ;{ }^{1} \mathrm{H}$ NMR $(500 \mathrm{MHz}$, $\left.\mathrm{CD}_{3} \mathrm{OD}, 323 \mathrm{~K}\right): \delta=5.23$ (bs, $\left.1 \mathrm{H}, \mathrm{H}-1\right), 3.92$ (m, 2H, $\mathrm{CH}_{2} \mathrm{NHCS}$ ), $3.86\left(\mathrm{dd}, 1 \mathrm{H}, J_{6 \mathrm{a}, 6 \mathrm{~b}}=12.0 \mathrm{~Hz}, J_{5,6 \mathrm{a}}=2.5 \mathrm{~Hz}, \mathrm{H}-6 \mathrm{a}\right), 3.65(\mathrm{dd}, 1 \mathrm{H}$, $\left.J_{5,6 \mathrm{~b}}=5.5 \mathrm{~Hz}, \mathrm{H}-6 \mathrm{~b}\right), 3.46\left(\mathrm{t}, 1 \mathrm{H}, J_{2,3}=J_{3,4}=9.5 \mathrm{~Hz}, \mathrm{H}-3\right), 3.44$ (m, 1H, H-5), 3.38 (dd, $\left.1 \mathrm{H}, J_{1,2}=9.5 \mathrm{~Hz}, \mathrm{H}-2\right), 3.34(\mathrm{dd}, 1 \mathrm{H}$, $\left.J_{4,5}=9.5 \mathrm{~Hz}, \mathrm{H}-4\right), 3.20$ (m, 2H, CH $\left.\mathrm{H}_{2} \mathrm{NHr}\right), 1.45$ (s, 9H, $\mathrm{CMe}_{3}$ ); ${ }^{13} \mathrm{C}$ NMR (125.7 MHz, $\mathrm{CD}_{3} \mathrm{OD}, 323 \mathrm{~K}$ ): $\delta=186.7$ (CS), 159.3 (CO carbamate), 85.9 (C-1), $80.5\left(\mathrm{CMe}_{3}, \mathrm{C}-5\right) 72.7$ (C-2), 70.1 (C-4), 63.0 (C-6), 61.8 (C-3), $42.8\left(\mathrm{CH}_{2} \mathrm{NHCS}\right), 40.9\left(\mathrm{CH}_{2} \mathrm{NH}_{2}\right), 28.8$ $\left(\mathrm{CMe}_{3}\right)$; ESIMS: $m / z=403\left[\mathrm{M}+\mathrm{Na}^{+}\right], 381\left(63 \%,\left[\mathrm{M}+\mathrm{H}^{+}\right]\right)$; anal. calcd for $\mathrm{C}_{14} \mathrm{H}_{28} \mathrm{~N}_{4} \mathrm{O}_{6} \mathrm{~S}$ : C, 44.20; $\mathrm{H}, 7.42 ; \mathrm{N}, 14.73$. Found: $\mathrm{C}$, 43.88; H, 7.21; N, 14.52.
Heptakis[2,3-di-O-hexanoyl-6-[2-[ $N^{\prime}\left[-2-\left[N^{\prime}\right.\right.$-(6-deoxy-6-tert-butoxycarbonylamino- $\beta$-D-glucopyranosyl)thioureido] ethyl]-thioureido]ethylthio]]cyclomaltoheptaose (18). To a solution of $17^{33}$ (44 mg, $13.6 \mu \mathrm{mol})$ in $\mathrm{DCM}(1 \mathrm{~mL}), \mathrm{Et}_{3} \mathrm{~N}(16 \mu \mathrm{L}, 0.11 \mathrm{mmol}, 1.1$ eq. $)$ and 14 (40 mg, $0.105 \mathrm{mmol}, 1.1$ eq.) in DMF ( $2 \mathrm{~mL}$ ) were added and the reaction mixture was stirred at rt for 7 days. The solvent was removed under vacuum and the residue was purified by column chromatography (70:10:1 DCM-MeOH- $\left.\mathrm{H}_{2} \mathrm{O}\right)$. Yield: $61 \mathrm{mg}(76 \%) ; R_{\mathrm{f}}=0.35\left(70: 10: 1\right.$ DCM-MeOH$\left.-\mathrm{H}_{2} \mathrm{O}\right) ;[\alpha]_{\mathrm{D}}=$ +34.0 (c 1.0, MeOH); ${ }^{1} \mathrm{H}$ NMR (500 MHz, DMSO- $d_{6}, 343 \mathrm{~K}$ ): $\delta=7.72\left(\mathrm{bs}, 7 \mathrm{H}, \mathrm{NH}-1_{\mathrm{Glc}}\right), 7.64$ (bs, 7H, NH), 7.51 (bs, 7H, NH), 7.39 (bs, 7H, $\mathrm{NH}_{\text {Cyst }}$ ), 5.27 (t, 7H, $J_{2,3}=J_{3,4}=9.0 \mathrm{~Hz}, \mathrm{H}-3$ ), 5.09 (bs, 7H, H-1), 5.04 (bs, 7H, H-1 ${ }_{\mathrm{Glc}}$ ), 4.76 (bs, 7H, NH-6 ${ }_{\mathrm{Glc}}$ ), 4.73 $\left(\mathrm{dd}, 7 \mathrm{H}, J_{1,2}=4.0 \mathrm{~Hz}, \mathrm{H}-2\right), 4.15(\mathrm{~m}, 7 \mathrm{H}, \mathrm{H}-5), 3.90\left(\mathrm{t}, 7 \mathrm{H}, J_{4,5}=\right.$ $9.0 \mathrm{~Hz}, \mathrm{H}-4$ ), 3.64 (bs, 42H, $2 \mathrm{CH}_{2} \mathrm{NHCS}, \mathrm{CH}_{2} \mathrm{~N}_{\text {Cyst }}$ ), 3.38 (ddd, $\left.7 \mathrm{H}, J_{6 \mathrm{a}, 6 \mathrm{~b}}=14 \mathrm{~Hz}, J_{\mathrm{NH}, 6 \mathrm{a}}=6.0 \mathrm{~Hz}, J_{5,6 \mathrm{a}}=3.5 \mathrm{~Hz}, \mathrm{H}-6 \mathrm{a}_{\mathrm{Glc}}\right), 3.25$ $\left(\mathrm{m}, 7 \mathrm{H}, \mathrm{H}-5_{\mathrm{Glc}}\right), 3.24\left(\mathrm{t}, 7 \mathrm{H}, J_{2,3}=J_{3,4}=9.0 \mathrm{~Hz}, \mathrm{H}-3_{\mathrm{Glc}}\right), 3.22(\mathrm{~m}$, $\left.7 \mathrm{H}, \mathrm{H}-2_{\mathrm{Glc}}\right), 3.09$ (m, 14H, H-6a, H6b), 3.01 (t, 7H, $J_{4,5}=9.0 \mathrm{~Hz}$, $\mathrm{H}-4_{\mathrm{Glc}}$ ), $3.00\left(\mathrm{dd}, 7 \mathrm{H}, J_{5,6 \mathrm{~b}}=6.0 \mathrm{~Hz}, \mathrm{H}-6 \mathrm{~b}_{\mathrm{Glc}}\right), 2.80(\mathrm{bs}, 14 \mathrm{H}$, $\mathrm{CH}_{2} \mathrm{~S}_{\text {Cyst }}$ ), 2.36 (m, 14H, H-2a $\left.\mathrm{a}_{\mathrm{Hex}}\right), 2.21$ (m, 14H, H-2 $\mathrm{b}_{\mathrm{Hex}}$ ), 1.54 $\left(\mathrm{m}, 28 \mathrm{H}, \mathrm{H}-3_{\mathrm{Hex}}\right), 1.39$ (s, 63H, $\left.\mathrm{CMe}_{3}\right), 1.29\left(\mathrm{~m}, 56 \mathrm{H}, \mathrm{H}-4_{\mathrm{Hex}}\right.$, $\left.\mathrm{H}-5_{\mathrm{Hex}}\right), 0.87$ (m, 42H, H- $\left.6_{\mathrm{Hex}}\right) ;{ }^{13} \mathrm{C}$ NMR (125.7 MHz, DMSO- $d_{6}$, $313 \mathrm{~K}$ ): $\delta=184.2,183.2$ (CS), 172.9, 171.9 (CO ester), 156.3 (CO carbamate), 96.6 (C-1), $83.9\left(\mathrm{C}-1_{\mathrm{Glc}}\right), 79.1\left(\mathrm{CMe}_{3}\right), 78.4$ (C-4), 77.6 (C-3 $\left.3_{\mathrm{Glc}}\right), 77.6$ (C-5 $\left.{ }_{\mathrm{Glc}}\right), 73.1\left(\mathrm{C}-2_{\mathrm{Glc}}\right), 73.0$ (C-6), 72.2 (C-4 $\left.{ }_{\mathrm{Glc}}\right), 71.6$ (C-5), 70.6 (C-2, C-3), 44.1, 43.8, $44.3\left(\mathrm{CH}_{2} \mathrm{NHCS}\right)$, 42.4 (C-6 $\left.{ }_{\mathrm{Glc}}\right), 33.9,33.7$ (C-2 $\left.{ }_{\mathrm{Hex}}\right), 33.1\left(\mathrm{CH}_{2} \mathrm{~N}_{\mathrm{Cyst}}\right), 31.3,31.1$ $\left(\mathrm{C}-4_{\text {Hex }}\right), 28.7\left(\mathrm{CMe}_{3}\right), 24.3,24.2\left(\mathrm{C}-3_{\mathrm{Hex}}\right), 22.2$ (C-5 $\left.5_{\mathrm{Hex}}\right), 14.0$ (C-6 $6_{\text {Hex }}$ ); ESIMS: $m / z$ 2979.7 $[\mathrm{M}+2 \mathrm{~K}]^{2+}$; anal. calcd for $\mathrm{C}_{245} \mathrm{H}_{427} \mathrm{~N}_{35} \mathrm{O}_{84} \mathrm{~S}_{21}$ : C, 50.04; $\mathrm{H}, 7.32 ; \mathrm{N}, 8.34$. Found: $\mathrm{C}$, 49.89; H, 7.22; N, 8.18.

Heptakis[2,3-di-O-hexanoyl-6-[2-[ $N^{\prime}\left[-2-\left[N^{\prime}\right.\right.$-(6-amino-6-deoxy- $\beta$-Dglucopyranosyl)thioureido]ethyl]thioureido]ethylthio]]cyclomaltoheptaose heptahydrochloride (2). Compound 18 (46 mg, $7.8 \mu \mathrm{mol}$ ) was treated with TFA-DCM $(1: 1,2 \mathrm{~mL})$ at $\mathrm{rt}$ for $2 \mathrm{~h}$. Then, solvent was evaporated and acid traces were removed by co-evaporation with water, and the residue was freeze-dried from diluted HCl. Yield: $37 \mathrm{mg}(93 \%) ;[\alpha]_{\mathrm{D}}=+426.5(c$ 0.75, $\mathrm{MeOH})$; ${ }^{1} \mathrm{H}$ NMR (500 MHz, $\left.5: 1 \mathrm{CD}_{3} \mathrm{OD}-\mathrm{D}_{2} \mathrm{O}, 333 \mathrm{~K}\right): \delta=5.40(\mathrm{~m}, 7 \mathrm{H}$, $\left.\mathrm{H}-1_{\mathrm{Glc}}\right), 5.33\left(\mathrm{t}, 7 \mathrm{H}, J_{2,3}=J_{3,4}=9.0 \mathrm{~Hz}, \mathrm{H}-3\right), 5.19\left(\mathrm{~d}, 7 \mathrm{H}, J_{1,2}=3.6 \mathrm{~Hz}\right.$, $\mathrm{H}-1$ ), 4.86 (dd, 7H, $\left.J_{1,2}=4.0 \mathrm{~Hz}, \mathrm{H}-2\right), 4.20(\mathrm{~m}, 7 \mathrm{H}, \mathrm{H}-5), 3.94$ $\left(\mathrm{t}, 7 \mathrm{H}, J_{4,5}=9.0 \mathrm{~Hz}, \mathrm{H}-4\right), 3.70\left(\mathrm{~m}, 7 \mathrm{H}, \mathrm{H}-5_{\mathrm{Glc}}\right), 3.74$ (bs, $42 \mathrm{H}$, $2 \mathrm{CH}_{2} \mathrm{NHCS}, \mathrm{CH}_{2} \mathrm{~N}_{\text {Cyst }}$ ), 3.56 (t, 7H, $J_{2,3}=J_{3,4}=9.0 \mathrm{~Hz}, \mathrm{H}-3_{\mathrm{Glc}}$ ), $3.51\left(\mathrm{~m}, 7 \mathrm{H}, \mathrm{H}-2_{\mathrm{Glc}}\right), 3.46$ (ddd, $7 \mathrm{H}, J_{6 \mathrm{a}, 6 \mathrm{~b}}=14 \mathrm{~Hz}, J_{5,6 \mathrm{a}}=2.8 \mathrm{~Hz}$, H-6a $\mathrm{a}_{\mathrm{Glc}}$ ), 3.31 (m, 7H, H-4 $4_{\mathrm{Glc}}$ ), 3.18 (m, 14H, H-6a, H6b), 3.09 (dd, $7 \mathrm{H}, J_{5,6 \mathrm{~b}}=8.8 \mathrm{~Hz}, \mathrm{H}-6 \mathrm{~b}_{\mathrm{Glc}}$ ), 2.97 (bs, $14 \mathrm{H}, \mathrm{CH}_{2} \mathrm{~S}_{\mathrm{Cys}}$ ), 2.45-2.28 (m, 28H, $\left.\mathrm{CH}_{2} \mathrm{CO}\right), 1.66$ (m, 28H, $\left.\mathrm{CH}_{2} \mathrm{CH}_{2} \mathrm{CO}\right), 1.37(\mathrm{~m}, 56 \mathrm{H}$, $\left.\mathrm{CH}_{2} \mathrm{CH}_{3}, \mathrm{CH}_{2} \mathrm{CH}_{2} \mathrm{CH}_{3}\right), 0.95\left(\mathrm{~m}, 42 \mathrm{H}, \mathrm{CH}_{3}\right) ;{ }^{13} \mathrm{C}$ NMR (125.7 MHz, DMSO- $d_{6}, 323 \mathrm{~K}$ ): $\delta=186.4,185.7$ (CS), 175.6, 174.5 (CO ester), 99.3 (C-1), 86.5 (C-1 $\left.1_{\mathrm{Glc}}\right), 80.1$ (C-4), 75.4 (C-3 $\left.3_{\mathrm{Glc}}\right), 74.5$ (C-5 ${ }_{\mathrm{Glc}}$ ), 74.6 (C-6, C-2 Glc $\left._{1}, \mathrm{C}-4_{\mathrm{Glc}}\right), 74.2$ (C-5), 73.3 (C-2, C-3), 48.9 (C-6 $\left.{ }_{\text {Glc }}\right), 46.8,46.5,46.1\left(\mathrm{CH}_{2} \mathrm{NHCS}, \mathrm{CH}_{2} \mathrm{~N}_{\text {Cyst }}\right), 36.5,36.4,35.7$ (C-2 $\left.{ }_{\text {Hex }}\right), 33.9,33.8$ (C. $\left.4_{\text {Hex }}\right), 32.0\left(\mathrm{CH}_{2} \mathrm{~S}_{\mathrm{Cyst}}\right), 27.0,26.9$ (C-3 $\left.3_{\mathrm{Hex}}\right)$, 24.9 (C-5 $\left.5_{\text {Hex }}\right), 16.7$ (C-6 $\left.{ }_{\text {Hex }}\right)$; ESIMS: $m / z 1727.1[\mathrm{M}+3 \mathrm{H}]^{3+}$; anal. calcd for $\mathrm{C}_{210} \mathrm{H}_{378} \mathrm{~N}_{35} \mathrm{O}_{70} \mathrm{~S}_{21}$ : C, 46.41; H, 7.01; N, 9.02. Found: C, 46.29; H, 6.88; N, 8.87. 
Heptakis[2,3-di-O-hexanoyl-6-[2-[ $N^{\prime}\left[-2-\left[N^{\prime}\right.\right.$-(3,6-dideoxy-3,6-ditert-butoxycarbonylamino- $\beta$-D-glucopyranosyl)thioureido]ethyl] thioureido]ethylthio]]cyclomaltoheptaose (19). To a solution of $17^{33}$ (86 mg, $\left.26.7 \mu \mathrm{mol}\right)$ in DCM (1 mL), $\mathrm{Et}_{3} \mathrm{~N}(23 \mu \mathrm{L}, 0.17 \mathrm{mmol}$, 1.1 eq.) and 15 (78 mg, $0.206 \mathrm{mmol}, 1.1$ eq.) in DMF (3 mL) were added and the reaction mixture was stirred at $\mathrm{rt}$ for 11 days, then concentrated. The solvent was removed under vacuum and the residue purified by column chromatography 70:10:1 $\rightarrow$ $70: 20: 1 \mathrm{DCM}-\mathrm{MeOH}-\mathrm{H}_{2} \mathrm{O}$ to give 19 as an amorphous solid. Yield: $91 \mathrm{mg}(52 \%) ; R_{\mathrm{f}}=0.50\left(70: 10: 1 \mathrm{DCM}-\mathrm{MeOH}-\mathrm{H}_{2} \mathrm{O}\right) ;[\alpha]_{\mathrm{D}}=$ +494 (c 1.0, MeOH); UV (MeOH): 285, $250 \mathrm{~nm}\left(\varepsilon_{\mathrm{mM}} 50.5,106.9\right)$; IR (KBr): $\nu_{\max }=3325,2957,2930,2856,1749,1698,150,1167$, $1040 \mathrm{~cm}^{-1}$; ${ }^{1} \mathrm{H}$ NMR (500 MHz, $\left.\mathrm{CD}_{3} \mathrm{OD}, 333 \mathrm{~K}\right): \delta=5.46(\mathrm{~d}, 7 \mathrm{H}$, $\left.J_{1,2}=9.5 \mathrm{~Hz}, \mathrm{H}-1_{\mathrm{Glc}}\right), 5.36$ (bs, 7H, H-3), 5.19 (bs, 7H, H-1), 4.86 (bs, $7 \mathrm{H}, \mathrm{H}-2), 4.57\left(\mathrm{t}, 14 \mathrm{H},{ }^{3} J_{\mathrm{H}, \mathrm{H}}=7.5 \mathrm{~Hz}, \mathrm{CH}_{2} \mathrm{NHCS}\right), 4.25$ (m, 7H, H-5), 3.96 (bs, 7H, H-4), $3.96\left(\mathrm{t}, 14 \mathrm{H},{ }^{3} J_{\mathrm{H}, \mathrm{H}}=7.8 \mathrm{~Hz}\right.$, $\mathrm{CH}_{2} \mathrm{~N}_{\text {Cyst }}$ ), 3.58 (dd, 7H, $J_{6 \mathrm{a}, 6 \mathrm{~b}}=14.0 \mathrm{~Hz}, J_{5,6 \mathrm{a}}=2.0 \mathrm{~Hz}, \mathrm{H}-6 \mathrm{a}_{\mathrm{Glc}}$ ), $3.56\left(\mathrm{~m}, 28 \mathrm{H}, \mathrm{CH}_{2} \mathrm{NHCS}, \mathrm{CH}_{2} \mathrm{~S}_{\mathrm{Cyst}}\right), 3.52\left(\mathrm{t}, 7 \mathrm{H}, J_{2,3}=9.5 \mathrm{~Hz}\right.$, $\mathrm{H}-2_{\mathrm{Glc}}$ ), 3.46 (t, 7H, $J_{3,4}=9.5 \mathrm{~Hz}, \mathrm{H}-3_{\mathrm{Glc}}$ ), 3.41 (ddd, 7H, $J_{4,5}=$ $\left.9.5 \mathrm{~Hz}, J_{5,6 \mathrm{~b}}=7.5 \mathrm{~Hz}, \mathrm{H}-5_{\mathrm{Glc}}\right), 3.29\left(\mathrm{t}, 7 \mathrm{H}, \mathrm{H}-4_{\mathrm{Glc}}\right), 3.28(\mathrm{~m}, 14 \mathrm{H}$, H-6a, H6b), 3.17 (dd, 7H, H-6b $\mathrm{Glc}_{\mathrm{Gl}}$ ), 2.52-2.24 (m, 28H, H-2 ${ }_{\mathrm{Hex}}$ ), $1.66\left(\mathrm{~m}, 28 \mathrm{H}, \mathrm{H}-3_{\mathrm{Hex}}\right), 1.47,1.46\left(2 \mathrm{~s}, 63 \mathrm{H}\right.$ each, $\left.2 \mathrm{CMe}_{3}\right), 1.42-$ $1.30\left(\mathrm{~m}, 56 \mathrm{H}, \mathrm{H}-4_{\mathrm{Hex}}, \mathrm{H}-5_{\mathrm{Hex}}\right), 0.96\left(\mathrm{~m}, 42 \mathrm{H}, \mathrm{H}-6_{\mathrm{Hex}}\right) ;{ }^{13} \mathrm{C} \mathrm{NMR}$ (125.7 MHz, $\left.\mathrm{CD}_{3} \mathrm{OD}, 333 \mathrm{~K}\right): \delta=185.5,181.5$ (CS), 175.9, 174.7 (CO ester), 160.4, 159.8 (2 CO carbamate), 99.4 (C-1), 88.5 $\left(\mathrm{C}-1_{\mathrm{Glc}}\right), 81.8\left(\mathrm{CMe}_{3}\right), 80.6\left(\mathrm{C}-4, \mathrm{C}-5_{\mathrm{Glc}}\right), 74.2(\mathrm{C}-5), 73.9\left(\mathrm{C}-2_{\mathrm{Glc}}\right)$, 73.0 (C-6, C-2, C-3) 72.7 (C-4 $\left.4_{\mathrm{Glc}}\right), 63.3$ (C-3 $\left.{ }_{\mathrm{Glc}}\right), 54.6\left(\mathrm{CH}_{2} \mathrm{NHCS}\right)$, $53.9\left(\mathrm{CH}_{2} \mathrm{~N}_{\text {Cyst }}\right), 44.5$ (C-6 $\left.{ }_{\mathrm{Glc}}\right), 42.4\left(\mathrm{CH}_{2} \mathrm{NHCS}\right), 36.4,36.3\left(\mathrm{C}-2_{\mathrm{Hex}}\right)$, $35.2\left(\mathrm{CH}_{2} \mathrm{~S}_{\text {Cyst }}\right), 33.8,33.7\left(\mathrm{C}-4_{\mathrm{Hex}}\right), 30.0\left(\mathrm{CMe}_{3}\right), 26.8\left(\mathrm{C}-3_{\mathrm{Hex}}\right), 24.6$ $\left(\mathrm{C}-5_{\mathrm{Hex}}\right), 15.6,15.5$ (C-6 $\left.{ }_{\mathrm{Hex}}\right)$; anal. calcd for $\mathrm{C}_{280} \mathrm{H}_{490} \mathrm{~N}_{42} \mathrm{O}_{981} \mathrm{~S}_{21}$ : C, 51.15; H, 7.51; N, 8.95. Found: C, 50.87; H, 7.29; N, 8.71.

Heptakis[2,3-di-O-hexanoyl-6-[2-[ $N^{\prime}\left[-2-\left[N^{\prime}-(3,6-d i a m i n o-3,6-\right.\right.$ dideoxy- $\beta$-D-glucopyranosyl)thioureido]ethyl] thioureido]ethylthio]]cyclomaltoheptaose tetradecahydrochloride (3). Compound $19(81 \mathrm{mg}, 13.8 \mu \mathrm{mol})$ was treated with TFA-DCM $(1: 1,2 \mathrm{~mL})$ at $\mathrm{rt}$ for $4 \mathrm{~h}$. Then, solvent was evaporated and acid traces were removed by co-evaporation with water, and the residue was dissolved in $10 \mathrm{mM} \mathrm{HCl}$ and freeze-dried to yield the unprotected compound 3. Yield: $78 \mathrm{mg}$ (quantitative); $[\alpha]_{\mathrm{D}}=+470.6(c 1.0, \mathrm{MeOH}) ; \mathrm{UV}(\mathrm{MeOH}): 247,270 \mathrm{~nm}$ $\left(\varepsilon_{\mathrm{mM}} 62.8,35.5\right)$; IR $(\mathrm{KBr}): \nu_{\max }=2959,1789,1747,1676,1286$, $1039 \mathrm{~cm}^{-1}$; ${ }^{1} \mathrm{H}$ NMR (500 MHz, $\left.\mathrm{CD}_{3} \mathrm{OD}, 333 \mathrm{~K}\right): \delta=5.46(\mathrm{~d}, 7 \mathrm{H}$, $J_{1,2}=8.3 \mathrm{~Hz} \mathrm{H}-1_{\mathrm{Glc}}$ ), 5.35 (bs, 7H, H-3), 5.18 (bs, 7H, H-1), 4.84 (bs, 7H, H-2), 4.56 (m, 14H, CH $\mathrm{H}_{2} \mathrm{NHCS}$ ), 4.23 (bs, 7H, H-5), $4.00\left(\mathrm{t}, 14 \mathrm{H},{ }^{3} J_{\mathrm{H}, \mathrm{H}}=7.3 \mathrm{~Hz}, \mathrm{CH}_{2} \mathrm{~N}_{\mathrm{Cyst}}\right), 3.77\left(\mathrm{dd}, 7 \mathrm{H}, J_{2,3}=9.8 \mathrm{~Hz}\right.$, $\left.\mathrm{H}-2_{\mathrm{Glc}}\right), 3.76\left(\mathrm{~m}, 14 \mathrm{H}, \mathrm{H}-5_{\mathrm{Glc}}\right), 3.61\left(\mathrm{t}, 7 \mathrm{H}, J_{2,3}=J_{3,4}=9.1 \mathrm{~Hz}\right.$, $\mathrm{H}-3_{\mathrm{Glc}}$ ), $3.58\left(\mathrm{t}, 28 \mathrm{H},{ }^{3} J_{\mathrm{H}, \mathrm{H}}=7.3 \mathrm{~Hz}, \mathrm{CH}_{2} \mathrm{NHCS}, \mathrm{CH}_{2} \mathrm{~S}_{\mathrm{Cys}}\right), 3.47$ $\left(\mathrm{dd}, 7 \mathrm{H}, J_{6 \mathrm{a}, 6 \mathrm{~b}}=13.6 \mathrm{~Hz}, J_{5,6 \mathrm{a}}=3.1 \mathrm{~Hz}, \mathrm{H}-6 \mathrm{a}_{\mathrm{Glc}}\right), 3.25(\mathrm{~m}, 14 \mathrm{H}$, H-6a, H6b), 3.17 (t, 7H, $J_{4,5}=9.1 \mathrm{~Hz}, \mathrm{H}-4_{\mathrm{Glc}}$ ), 3.11 (dd, 7H, $J_{5,6 \mathrm{~b}}=$ $\left.8.8 \mathrm{~Hz}, \mathrm{H}-6 \mathrm{~b}_{\mathrm{Glc}}\right), 2.43-2.29\left(\mathrm{~m}, 28 \mathrm{H}, \mathrm{H}-2_{\mathrm{Hex}}\right), 1.64(\mathrm{~m}, 28 \mathrm{H}, \mathrm{H}-$ $\left.3_{\mathrm{Hex}}\right), 1.36$ (m, 56H, H-5 $\left.{ }_{\mathrm{Hex}}, \mathrm{H}-4_{\mathrm{Hex}}\right), 0.94\left(\mathrm{~m}, 42 \mathrm{H}, \mathrm{H}-6_{\mathrm{Hex}}\right) ;{ }^{13} \mathrm{C}$ NMR (125.7 MHz, CD $\left.{ }_{3} \mathrm{OD}, 323 \mathrm{~K}\right): \delta=185.9$ (CS), 176.0, 174.8 (CO ester), 99.4 (C-1), 88.3 (C-1 Glc ), 86.1 (C-4), 81.6 (C-5 Glc $), 77.5$ (C-5), 76.0-68.7 (C-6, C-4 $\left.{ }_{\mathrm{Glc}}, \mathrm{C}-2, \mathrm{C}-3\right), 63.1$ (C-2 $\left.{ }_{\mathrm{Glc}}\right), 61.9\left(\mathrm{C}-3_{\mathrm{Glc}}\right)$, $54.7\left(\mathrm{CH}_{2} \mathrm{~N}_{\mathrm{Cyst}}\right), 49.4\left(\mathrm{C}-6_{\mathrm{Glc}}\right), 45.4,43.2,42.5\left(\mathrm{CH}_{2} \mathrm{NHCS}\right), 36.5$, 36.4 (C-2 $\left.{ }_{\mathrm{Hex}}\right), 33.7$ (C. $\left.4_{\mathrm{Hex}}\right), 31.9\left(\mathrm{CH}_{2} \mathrm{~S}_{\mathrm{Cyst}}\right), 26.8$ (C-3 $\left.3_{\mathrm{Hex}}\right), 24.7$
$\left(\mathrm{C}-5_{\mathrm{Hex}}\right), 15.5\left(\mathrm{C}-6_{\mathrm{Hex}}\right)$; anal. calcd for $\mathrm{C}_{210} \mathrm{H}_{392} \mathrm{~N}_{42} \mathrm{O}_{70} \mathrm{~S}_{21}$ : C, 44.38; H, 6.95; N, 10.35. Found: C, 44.01; H, 6.62; N, 9.97; S, 11.49 .

Heptakis[2,3-di-O-hexanoyl-6-[2-[ $N^{\prime}\left[-2-\left[N^{\prime}\right.\right.$-(3-deoxy-3-tert-butoxycarbonylamino- $\beta$-D-glucopyranosyl)thioureido] ethyl]-thioureido]ethylthio]]cyclomaltoheptaose (20). To a solution of $17^{33}(32 \mathrm{mg}$, $9.9 \mu \mathrm{mol})$ in DMF $(1.3 \mathrm{~mL})$ a solution of $\mathrm{Et}_{3} \mathrm{~N}(9.5 \mu \mathrm{L}, 69 \mu \mathrm{mol}$, 1 eq.) and 16 (29 mg, $76 \mu \mathrm{mol}, 1.1$ eq.) in DMF (1.5 mL) were added and the reaction mixture was stirred at $\mathrm{rt}$ for 7 days, then concentrated. The solvent was removed under vacuum and the residue was purified by column chromatography 70:20:1 $\rightarrow$ $70: 10: 1$ DCM-MeOH$-\mathrm{H}_{2} \mathrm{O}$, to give 20. Yield: $37 \mathrm{mg}(64 \%)$; $R_{\mathrm{f}}=0.53\left(70: 20: 1\right.$ DCM-MeOH- $\left.\mathrm{H}_{2} \mathrm{O}\right) ;[\alpha]_{\mathrm{D}}=+59.0$ (c 1.0, DCM); UV (DCM): $247 \mathrm{~nm}\left(\varepsilon_{\mathrm{mM}} 206.1\right)$; IR (NaCl): $\nu_{\max }=3319$, 2957, 1750, 1693, 1247, 1165, $1038 \mathrm{~cm}^{-1}$; ${ }^{1} \mathrm{H}$ NMR $(500 \mathrm{MHz}$, $\left.\mathrm{CD}_{3} \mathrm{OD}, 323 \mathrm{~K}\right): \delta=5.31$ (bt, 7H, H-3), 5.26 (bs, 7H, H-1 $\mathrm{Glc}_{\mathrm{c}}$ ), 5.17 (d, 7H, $\left.J_{1,2}=3.0 \mathrm{~Hz}, \mathrm{H}-1\right), 4.84(\mathrm{~m}, 7 \mathrm{H}, \mathrm{H}-2), 4.18$ (m, 7H, H-5), $3.90\left(\mathrm{t}, 7 \mathrm{H}, J_{4,5}=8.5 \mathrm{~Hz}, \mathrm{H}-4\right), 3.89\left(\mathrm{bd}, 7 \mathrm{H}, J_{6 \mathrm{a}, 6 \mathrm{~b}}=12.5 \mathrm{~Hz}\right.$, $\mathrm{H}-6 \mathrm{a}_{\mathrm{Glc}}$ ), 3.76 (bs, 42H, $\left.2 \mathrm{CH}_{2} \mathrm{NHCS}, \mathrm{CH}_{2} \mathrm{~N}_{\text {Cyst }}\right), 3.73(\mathrm{~m}, 7 \mathrm{H}$, $\left.\mathrm{H}-6 \mathrm{~b}_{\mathrm{Glc}}\right), 3.53-3.40\left(\mathrm{~m}, 28 \mathrm{H}, \mathrm{H}-5_{\mathrm{Glc}}, \mathrm{H}-3_{\mathrm{Glc}}, \mathrm{H}-2_{\mathrm{Glc}}, \mathrm{H}-4_{\mathrm{Glc}}\right), 3.28$ (m, 7H, H-6a), 3.17 (m, 7H, H6b), 2.93 (bs, 14H, $\mathrm{CH}_{2} \mathrm{~S}_{\mathrm{Cys}}$ ), 2.42 $\left(\mathrm{m}, 14 \mathrm{H}, \mathrm{H}-2_{\mathrm{Hex}}\right), 2.33\left(\mathrm{~m}, 7 \mathrm{H}, \mathrm{H}-2 \mathrm{a}_{\mathrm{Hex}}\right), 2.25\left(\mathrm{~m}, 7 \mathrm{H}, \mathrm{H}-2 \mathrm{~b}_{\mathrm{Hex}}\right)$, $1.63\left(\mathrm{~m}, 28 \mathrm{H}, \mathrm{H}-3_{\mathrm{Hex}}\right), 1.45\left(\mathrm{~s}, 63 \mathrm{H}, \mathrm{CMe}_{3}\right), 1.32\left(\mathrm{~m}, 56 \mathrm{H}, \mathrm{H}-5_{\mathrm{Hex}}\right.$, $\left.\mathrm{H}-3_{\mathrm{Hex}}\right), 0.89$ (m, 42H, H-6 $\left.{ }_{\mathrm{Hex}}\right) ;{ }^{13} \mathrm{C} \mathrm{NMR}\left(125.7 \mathrm{MHz}, \mathrm{CD}_{3} \mathrm{OD}\right.$, $323 \mathrm{~K}$ ): $\delta=183.9,182.7$ (CS), 173.4, 172.1 (CO ester), 157.8 (CO carbamate), 96.8 (C-1), 84.6 (C-1 $\left.1_{\mathrm{Glc}}\right), 79.5\left(\mathrm{CMe}_{3}\right), 79.3$ (C-4 $\left.4_{\mathrm{Glc}}\right)$, 79.0 (C-4, C-5 Glc $_{\ddagger}$ ), 71.9 (C-5), 71.1 (C-3), 70.6 (C-2), 68.5 (C-2 Glc ), 61.3 (C-6 $\left.{ }_{\text {Glc }}\right), 60.5$ (C-3 $\left.3_{\text {Glc }}\right), 45.0,44.0\left(\mathrm{CH}_{2} \mathrm{NHCS}, \mathrm{CH}_{2} \mathrm{~N}_{\text {Cyst }}\right), 33.8$, 33.7 (C-6, C-2 $\left.{ }_{\mathrm{Hex}}\right), 32.7\left(\mathrm{CH}_{2} \mathrm{~S}_{\mathrm{Cyst}}\right), 31.2,31.1$ (C-4 $\left.4_{\mathrm{Hex}}\right), 27.6$ $\left(\mathrm{C}-3_{\mathrm{Hex}}\right), 24.2\left(\mathrm{CMe}_{3}\right), 22.1\left(\mathrm{C}-5_{\mathrm{Hex}}\right), 13.1\left(\mathrm{C}-6_{\mathrm{Hex}}\right)$. Anal. calcd for $\mathrm{C}_{245} \mathrm{H}_{427} \mathrm{~N}_{35} \mathrm{O}_{84} \mathrm{~S}_{21}$ : C, 50.04; H, 7.32; N, 8.34, S, 11.45. Found: C, 49.78; H, 6.98; N, 8.01; S, 11.03.

Heptakis[2,3-di-O-hexanoyl-6-[2-[ $N^{\prime}\left[-2-\left[N^{\prime}\right.\right.$-(3-amino-3-deoxy- $\beta$-Dglucopyranosyl)thioureido]ethyl]thioureido]ethylthio]]cyclomaltoheptaose heptahydrochloride (4). Compound 20 (36 mg, $5.5 \mu \mathrm{mol})$ was treated with TFA-DCM $(1: 1,2 \mathrm{~mL})$ at rt for $4 \mathrm{~h}$. Then, solvent was evaporated and acid traces were removed by co-evaporation with water, and the residue was dissolved in $10 \mathrm{mM} \mathrm{HCl}$ and freeze-dried to yield the unprotected compound 4. Yield: $30 \mathrm{mg}$ (quantitative); $[\alpha]_{\mathrm{D}}=+27.8(c 1.0, \mathrm{MeOH})$; UV (MeOH): $339 \mathrm{~nm}\left(\varepsilon_{\mathrm{mM}} 1.1\right)$; IR (KBr): $\nu_{\max }=3288,2959,1760$, 1667, $1035 \mathrm{~cm}^{-1} ;{ }^{1} \mathrm{H}$ NMR (500 MHz, $\left.\mathrm{CD}_{3} \mathrm{OD}, 333 \mathrm{~K}\right): \delta=5.44$ (m, 7H, H-1 $\mathrm{Glc}_{\mathrm{Gl}}$ ), 5.31 (bs, 7H, H-3), 5.16 (bs, 7H, H-1), 4.83 (bs, 7H, $\mathrm{H}-2), 4.18$ (m, 7H, H-5), $3.90(\mathrm{~m}, 7 \mathrm{H}, \mathrm{H}-4), 3.88$ (bd, 7H, $J_{6 \mathrm{a}, 6 \mathrm{~b}}=$ $11.5 \mathrm{~Hz}, \mathrm{H}-6 \mathrm{a}_{\mathrm{Glc}}$ ), 3.77 (bs, 42H, $2 \mathrm{CH}_{2} \mathrm{NHCS}, \mathrm{CH}_{2} \mathrm{~N}_{\mathrm{Cyst}}$ ), 3.72-3.59 (m, 21H, H-2 $\left.{ }_{\mathrm{Glc}}, \mathrm{H}-4_{\mathrm{Glc}}, \mathrm{H}-6 \mathrm{~b}_{\mathrm{Glc}}\right), 3.53$ (m, 7H, H-5 $5_{\mathrm{Glc}}$ ), 3.27 (m, 7H, H-6a), 3.17 (m, 14H, H-6b, H-3 ${ }_{\text {Glc }}$ ), 2.96 (bs, $14 \mathrm{H}, \mathrm{CH}_{2} \mathrm{~S}_{\mathrm{Cys}}$ ), 2.42-2.24 (m, 28H, H-2 ${ }_{\text {Hex }}$ ), 1.63 (m, 28H, H-3 ${ }_{\text {Hеx }}$ ), 1.37-1.28 (m, $\left.56 \mathrm{H}, \mathrm{H}-5_{\mathrm{Hex}}, \mathrm{H}-4_{\mathrm{Hex}}\right), 0.91$ (m, 42H, H- $\left.6_{\mathrm{Hex}}\right) ;{ }^{13} \mathrm{C} \mathrm{NMR}(125.7 \mathrm{MHz}$, $\mathrm{CD}_{3} \mathrm{OD}, 333 \mathrm{~K}$ ): $\delta=185.6,183.4$ (CS), 174.7, 173.4 (CO ester), 98.2 (C-1), 85.6 (C-1 Glc $\left._{1}\right), 80.0$ (C-5 $\left.{ }_{\mathrm{Glc}}, \mathrm{C}-4\right), 73.2$ (C-5), 71.9 (C-3), 71.6 (C-2), 70.3 (C-4 $\left.{ }_{\mathrm{Glc}}\right), 67.6$ (C-2 $\left.{ }_{\mathrm{Glc}}\right), 61.9\left(\mathrm{C}-6_{\mathrm{Glc}}\right), 61.0\left(\mathrm{C}-3_{\mathrm{Glc}}\right), 45.4$, 45.0, $44.3\left(\mathrm{CH}_{2} \mathrm{NHCS}, \mathrm{CH}_{2} \mathrm{~N}_{\text {Cyst }}\right.$ ), 35.1, 35.0 (C-6, C-2 $\left.{ }_{\mathrm{Hex}}\right), 34.0$ $\left(\mathrm{CH}_{2} \mathrm{~S}_{\mathrm{Cyst}}\right), 32.5,32.4\left(\mathrm{C}-4_{\mathrm{Hex}}\right), 25.5$ (C-3 $\left.{ }_{\mathrm{Hex}}\right), 23.4\left(\mathrm{C}-5_{\mathrm{Hex}}\right), 14.4$,

$\ddagger$ Assignment of the signal can be exchanged. 
14.3 (C-6 $\left.6_{\text {Hex }}\right)$. Anal. calcd for $\mathrm{C}_{210} \mathrm{H}_{378} \mathrm{~N}_{35} \mathrm{O}_{70} \mathrm{~S}_{21}$ : C, 46.41; H, 7.01; N, 9.02; S, 12.39. Found: C, 46.07; H, 6.73; N, 8.76; S, 12.10.

\section{Preparation of nanocomplexes composed of pGaCD 2-4 and pDNA (pTG11236)}

The plasmid pTG11236 (pCMV-SV40-luciferase-SV40pA), used for the preparation of the pDNA complexes and for transfection assay, is a plasmid of $5739 \mathrm{bp}$ (base pairs). The quantities of compound used were calculated according to the desired pDNA concentration of $0.1 \mathrm{mg} \mathrm{mL}^{-1}$ (303 $\mu \mathrm{M}$ phosphate), the N/P ratio, the molar weight and the number of protonable nitrogens in the selected CD derivative or Jet-PEI. ${ }^{47,48}$ Experiments were performed for N/P 5 and 10. Concerning the preparation of the DNA complexes from CD derivatives and Jet-PEI, pDNA was diluted in HEPES ( $20 \mathrm{mM}, \mathrm{pH} 7.4)$ to a final concentration of $303 \mu \mathrm{M}$, and then the desired amount of $\mathrm{CD}$ derivative was added from 10 or $20 \mathrm{mM}$ stock solution (DMSO). For Jet-PEI polyplexes, pDNA was diluted in a $150 \mathrm{mM} \mathrm{NaCl}$ solution to a final phosphate concentration of $303 \mu \mathrm{M}$, and then the desired amount of Jet-PEI was added from a $7.5 \mathrm{mM}$ water solution. The preparation was vortexed for $2 \mathrm{~h}$ and used for characterization or transfection experiments.

\section{Agarose gel electrophoresis}

Each CD derivative/pDNA formulation $(20 \mu \mathrm{L}, 0.4 \mu \mathrm{g}$ of plasmid $)$ was submitted to electrophoresis for about $30 \mathrm{~min}$ under $150 \mathrm{~V}$ through a $0.8 \%$ agarose gel in TAE $1 \times$ (Tris-acetate-EDTA) buffer and stained by spreading a solution of ethidium bromide (EtBr, Sigma) in TAE buffer ( $20 \mu \mathrm{L}$ of EtBr in a $10 \mathrm{mg} \mathrm{mL}^{-1}$ solution of $200 \mathrm{~mL}$ of TAE). The DNA was then visualized after photographing on an UV transilluminator. The plasmid integrity in each sample was confirmed by electrophoresis after decomplexation with sodium dodecyl sulfate (SDS, 8\%).

\section{Measurement of CDplex size and of the $\xi$-potential by dynamic light scattering (DLS)}

The average size of the glycoCDplexes was measured using a Zetasizer Nano (Malvern Instruments, Paris, France) with the following specification: sampling time, automatic; number of measurements, 3 per sample; medium viscosity, $1.054 \mathrm{cP}$; refractive index, 1.33; scattering angle, $173^{\circ} ; \lambda=633 \mathrm{~nm}$; temperature, $25{ }^{\circ} \mathrm{C}$. Data were analyzed using the multimodal number distribution software included in the instrument. Results are given as volume distribution of the major population by the mean diameter with its standard deviation. Zeta potential measurements on the glycoCDplexes were made with the same apparatus using "Mixed Mode Measurement" phase analysis light scattering (M3-PALS).

M3 consists of both slow field reversal and fast field reversal measurements, hence the name 'Mixed Mode Measurement' that improves accuracy and resolution. The following specifications were applied: sampling time, automatic; number of measurements, 3 per sample; medium viscosity, $1.054 \mathrm{cP}$; medium dielectric constant, 80; temperature, $25^{\circ} \mathrm{C}$.

Before each series of experiments, the performance of the instruments was checked with either $90 \mathrm{~nm}$ monodisperse latex beads (Coulter) for DLS or with DTS 50 standard solution (Malvern) for zeta potentials.

\section{Transmission electron microscopy (TEM)}

Formvar-carbon coated grids previously made hydrophilic by glow discharge were placed on top of small drops of the CDplex samples (HEPES $20 \mathrm{mM}, \mathrm{pH}$ 7.4, pDNA $303 \mu \mathrm{M}$ phosphate) prepared as described above. After 1-3 min of contact, grids were negatively stained with a few drops of $1 \%$ aqueous solution of uranyl acetate. The grids were then dried and observed using a Philips CM12 electron microscope working under standard conditions. All these experiments were reproduced twice on each formulation.

\section{Cell-based assays}

Twenty-four hours before transfection, COS-7 cells were grown at a density of $2 \times 10^{4}$ cells per well in a 96-well plates in Dulbecco's modified Eagle culture medium (DMEM; GibcoBRL) containing $10 \%$ foetal calf serum (FCS; Sigma) and 100 units per mg penicillin and $100 \mu \mathrm{g} \mathrm{mL} \mathrm{m}^{-1}$ streptomycin in a wet $\left(37^{\circ} \mathrm{C}\right)$ and $5 \% \mathrm{CO}_{2} / 95 \%$ air atmosphere. The above described CDplexes and Jet-PEI:pDNA polyplexes were diluted to $100 \mu \mathrm{L}$ in DMEM or in DMEM supplemented with $10 \%$ FCS in order to have $0.5 \mu \mathrm{g}$ of pDNA in the well ( $15 \mu \mathrm{M}$ phosphate). The culture medium was removed and replaced by $100 \mu \mathrm{L}$ of these complexes. After $4 \mathrm{~h}$ and $24 \mathrm{~h}, 50$ and $100 \mu \mathrm{L}$ of DMEM supplemented with $30 \%$ and $10 \%$ FCS, respectively, were added. After $48 \mathrm{~h}$, the transfection was stopped, the culture medium was discarded, and the cells washed twice with $100 \mu \mathrm{L}$ of PBS and lysed with $50 \mu \mathrm{L}$ of lysis buffer (Promega, Charbonnières, France). The lysates were frozen at $-32{ }^{\circ} \mathrm{C}$, before the analysis of luciferase activity. This measurement was performed on a luminometer (GENIOS PRO, Tecan France S.A) in dynamic mode, for $10 \mathrm{~s}$ on $20 \mu \mathrm{L}$ on the lysis mixture and using the "luciferase" determination system (Promega) in 96-well plates. The total protein concentration per well was determined by the BCA test (Pierce, Montluçon, France). Luciferase activity was calculated as femtograms (fg) of luciferase per $\mathrm{mg}$ of protein. The percentage of cell viability was calculated as the ratio of the total protein amount per well of the transfected cells relative to that measured for untreated cells $\times 100$. The data were calculated from three or four repetitions in two fully independent experiments (formulation and transfection).

\section{Statistical analysis}

Statistical tests were performed using STATGRAPHICS Plus 5.0 software. Analysis of variance (Anova) was run on the logarithmic transformation of transfection levels (Log 10 [fg luciferase/ $\mathrm{mg}$ protein]) and on the cell viability to fit normal distributions of the data. Two factors, i.e. the nature of the complexing agent (the $\mathrm{CD}$ derivative and Jet-PEI) and the N/P ratio, were analyzed as sources of the variation of logarithmic transformation of the transfection levels and of cell variability percentages using a multiple comparison procedure. Tukey's honestly significant difference (HSD) method was used to discriminate between the 
means of cell viability percentages and the logarithmic transformation of luciferase expression levels.

\section{Acknowledgements}

This work was supported by the Spanish Ministerio de Economía y Competitividad (MinECo; contract numbers CTQ2010-15848 and SAF2010-15670), the Junta de Andalucía, the CSIC, the CNRS, and FUSINT (CNRS project).

\section{Notes and references}

1 J. Grisham, Nat. Biotechnol., 2000, 18, 254.

2 S. Nayak and R. W. Herzog, Gene Ther., 2010, 17, 295.

3 S. Ylä-Herttuala, Mol. Ther., 2012, 20, 1831.

4 T. Wirth, N. Parker and S. Ylä-Herttuala, Gene, 2013, 525, 162-169.

5 M. A. Mintzer and E. E. Simanek, Chem. Rev., 2009, 109, 259.

6 D. Glover, H. Lipps and D. Jans, Nat. Rev. Genet., 2005, 6, 299.

7 K. Miyata, N. Nishiyama and K. Kataoka, Chem. Soc. Rev., 2012, 41, 2562.

8 E. Wagner, Pharm. Res., 2004, 21, 8.

9 T. Niidome and L. Huang, Gene Ther., 2002, 9, 1647.

10 H. Akita and H. Harashima, Expert Opin. Drug Delivery, 2008, 5, 847.

11 B. Demeneix, Z. Hassani and J. Behr, Curr. Gene Ther., 2004, 4, 445.

12 M. E. Davis, Mol. Pharmaceutics, 2009, 6, 659.

13 M. E. Davis, J. E. Zuckerman, C. H. J. Choi, D. Seligson, A. Tolcher, C. A. Alabi, Y. Yen, J. D. Heidel and A. Ribas, Nature, 2010, 464, 1067.

14 D. Zhi, S. Zhang, S. Cui, Y. Zhao, Y. Wang and D. Zhao, Bioconjugate Chem., 2013, 24, 487.

15 J. Sunshine, J. J. Green, K. P. Mahon, F. Yang, A. A. Eltoukhy, D. N. Nguyen, R. Langer and D. G. Anderson, Adv. Mater., 2009, 21, 4947.

16 D. F. Zhi, S. B. Zhang, B. Wang, Y. N. Zhao, B. L. Yang and S. J. Yu, Bioconjugate Chem., 2010, 21, 563.

17 C. Ortiz Mellet, J. M. Benito and J. M. García Fernández, Chem. - Eur. J., 2010, 16, 6728.

18 V. Bagnacani, V. Franceschi, M. Basi, M. Lomazzi, G. Donofrio, F. Sansone, A. Casnati and R. Ungaro, Nat. Commun., 2013, 4, 1721, and references therein.

19 D. Sigwalt, M. Holler, J. Iehl, J.-F. Nierengarten, M. Nothisen, E. Morin and J.-S. Remy, Chem. Commun., 2011, 47, 4640.

20 I. Nierengarten, M. Nothisen, D. Sigwalt, T. Biellmann, M. Holler, J.-S. Remy and J.-F. Nierengarten, Chem. - Eur. J., 2013, 19, 17552.

21 L. Gallego-Yerga, M. J. González-Álvarez, N. Mayordomo, F. Santoyo-González, J. M. Benito, C. Ortiz Mellet, F. Mendicuti and J. M. García Fernández, Chem. - Eur. J., 2014, 20, 6622, and references therein.

22 S. Srinivasachari, K. M. Fichter and T. M. Reineke, J. Am. Chem. Soc., 2008, 130, 4618.
23 B. M. D. C. Godinho, D. J. McCarthy, C. Torres-Fuentes, C. J. Beltrán, J. McCarthy, A. Quinlan, J. R. Ogier, R. Darcy, C. M. O'Driscoll and J. F. Cryan, Biomaterials, 2014, 35, 489, and references therein.

24 C. Ortiz Mellet, J. M. García Fernández and J. M. Benito, Chem. Soc. Rev., 2011, 40, 1586.

25 J. M. García Fernández, J. M. Benito and C. Ortiz Mellet, Pure Appl. Chem., 2013, 85, 1825.

26 C. Aranda, K. Urbiola, A. Méndez Ardoy, J. M. García Fernández, C. Ortiz Mellet and C. Tros de Ilarduya, Eur. J. Pharm. Biopharm., 2013, 85, 390.

27 A. Díaz-Moscoso, N. Guilloteau, C. Bienvenu, A. MéndezArdoy, J. L. Jiménez Blanco, J. M. Benito, L. Le Gourrierec, C. Di Giorgio, P. Vierling, J. Defaye, C. Ortiz Mellet and J. M. García Fernández, Biomaterials, 2011, 32, 7263.

28 N. Symens, A. Méndez-Ardoy, A. Díaz-Moscoso, E. SánchezFernández, K. Remaut, J. Demeester, J. M. García Fernández, S. C. De Smedt and J. Rejman, Bioconjugate Chem., 2012, 23, 1276.

29 L. Desigaux, M. Sainlos, O. Lambert, R. Chevre, E. LetrouBonneval, J. Vigneron, P. Lehn, J. Lehn and B. Pitard, Proc. Natl. Acad. Sci. U. S. A., 2007, 104, 16534.

30 A. Ghilardi, D. Pezzoli, M. C. Bellucci, C. Malloggi, A. Negri, A. Sganappa, G. Tedeschi, G. Candiani and A. Volonterio, Bioconjugate Chem., 2013, 24, 1928.

31 Y. Zhang, J. M. Pelet, D. A. Heller, Y. Dong, D. Chen, Z. Gu, B. J. Joseph, J. Wallas and D. G. Anderson, Adv. Mater., 2013, 25, 4641.

32 C. Ortiz Mellet, J. M. García Fernández and J. M. Benito, Carbohydr. Chem., 2012, 38, 338-375.

33 A. Díaz-Moscoso, L. Le Gourrierec, M. Gomez-García, J. M. Benito, P. Balbuena, F. Ortega-Caballero, N. Guilloteau, C. Di Giorgio, P. Vierling, J. Defaye, C. Ortiz Mellet and J. M. García Fernández, Chem. - Eur. J., 2009, 15, 12871.

34 A. Méndez-Ardoy, N. Guilloteau, C. Di Giorgio, P. Vierling, F. Santoyo-González, C. Ortiz Mellet and J. M. García Fernández, J. Org. Chem., 2011, 76, 5882.

35 A. Méndez-Ardoy, M. Gómez-García, C. Ortiz-Mellet, N. Sevillano, M. D. Girón, R. Salto, F. Santoyo-González and J. M. García Fernández, Org. Biomol. Chem., 2009, 7, 2681.

36 Á. Martínez, C. Bienvenu, J. L. Jiménez Blanco, P. Vierling, C. Ortiz Mellet, J. M. García Fernández and C. Di Giorgio, J. Org. Chem., 2013, 78, 8143.

37 J. L. Jiménez Blanco, P. Bootello, J. M. Benito, C. Ortiz Mellet and J. M. García Fernández, J. Org. Chem., 2006, 71, 5136.

38 J. L. Jiménez Blanco, F. Ortega-Caballero, C. Ortiz Mellet and J. M. García Fernández, Beilstein J. Org. Chem., 2010, 6, 20.

39 Á. Martínez, C. Ortiz Mellet and J. M. García Fernández, Chem. Soc. Rev., 2013, 42, 4746.

40 J. L. Jiménez Blanco, P. Bootello, R. Gutiérrez Gallego, C. Ortiz Mellet and J. M. García Fernández, Synthesis, 2007, 2545.

41 J. Loccufier, J. Crommen, J. Vandorpe and E. Schacht, Makromol. Chem., Rapid Commun., 1991, 12, 159. 
$42 \mathrm{~N} / \mathrm{P}$ ratios were estimated considering all potentially ionizable groups on pGaCD and pDNA, respectively. For a revealing discussion of considering the effective charges when formulating transfectious NPs, see: M. Muñoz-Úbeda, S. K. Misra, A. L. Barrán-Berdón, C. Aicart-Ramos, M. B. Sierra, J. Biswas, P. Kondaiah, E. Junquera, S. Bhattacharya and E. Aicart, J. Am. Chem. Soc., 2011, 133, 18014.

43 A. Díaz-Moscoso, D. Vercauteren, J. Rejman, J. M. Benito, C. Ortiz Mellet, S. C. De Smedt and J. M. García Fernández, J. Controlled Release, 2010, 143, 318.

44 A. Díaz-Moscoso, P. Balbuena, M. Gomez-García, C. Ortiz Mellet, J. M. Benito, L. Gourrierec, C. Di Giorgio, P. Vierling,
A. Mazzaglia, N. Micali, J. Defaye and J. M. García Fernández, Chem. Commun., 2008, 2001.

45 S. Srinivasachari, K. M. Fichter and T. M. Reineke, J. Am. Chem. Soc., 2008, 130, 4618.

46 A. Méndez-Ardoy, K. Urbiola, C. Aranda, C. Ortiz Mellet, J. M. García Fernández and C. Tros de Ilarduya, Nanomedicine, 2011, 6, 1697.

47 M. Louis, S. Dutoit, Y. Denoux, P. Erbacher, E. Deslandes, J.-P. Behr, P. Gauduchon and L. Poulain, Cancer Gene Ther., 2006, 13, 367.

48 O. Boussif, F. Lezoualc'h, M. A. Zanta, M. D. Mergny, D. Scherman, B. Demeneix and J.-P. Behr, Proc. Natl. Acad. Sci. U. S. A., 1995, 92, 7297. 